Reihe Ökonomie Economics Series

\title{
An Integrated CVaR and Real Options Approach to Investments in the Energy Sector
}

Ines Fortin, Sabine Fuss, Jaroslava Hlouskova, Nikolay Khabarov, Michael Obersteiner, Jana Szolgayova 

Reihe Ökonomie Economics Series

\section{An Integrated CVaR and Real Options Approach to Investments in the Energy Sector}

Ines Fortin, Sabine Fuss, Jaroslava Hlouskova, Nikolay Khabarov, Michael Obersteiner, Jana Szolgayova

May 2007

Institut für Höhere Studien (IHS), Wien Institute for Advanced Studies, Vienna 


\section{Contact:}

Ines Fortin

IHS, Stumpergasse 56, 1060 Vienna, Austria

푤: 43/1/59991-165

Email: fortin@ins.ac.at

Sabine Fuss

University of Maastricht/UNU-Merit

Keizer Karelplein 19, 6211 TC

Maastricht, The Netherlands

要: +31/43/3884-430

email: S.Fuss@algec.unimaas.nl

Jaroslava Hlouskova

IHS, Stumpergasse 56, 1060 Vienna, Austria

푤: 43/1/59991-142

email: hlouskov@ihs.ac.at

Nikolay Khabarov

International Institute for Applied Systems Analysis (IIASA)

2361 Laxenburg, Austria

푤: +43/2236/807-346

email: khabarov@iiasa.ac.at

Michael Obersteiner

International Institute for Applied Systems Analysis (IIASA)

2361 Laxenburg, Austria

II: : +43/2236/807-460

email: oberstei@iiasa.ac.at

Jana Szolgayova

International Institute for Applied Systems Analysis (IIASA)

2361 Laxenburg, Austria

푤: $+43 / 2236 / 807-349$

email: szolgay@iiasa.ac.at

Founded in 1963 by two prominent Austrians living in exile - the sociologist Paul F. Lazarsfeld and the economist Oskar Morgenstern - with the financial support from the Ford Foundation, the Austrian Federal Ministry of Education and the City of Vienna, the Institute for Advanced Studies (IHS) is the first institution for postgraduate education and research in economics and the social sciences in Austria. The Economics Series presents research done at the Department of Economics and Finance and aims to share "work in progress" in a timely way before formal publication. As usual, authors bear full responsibility for the content of their contributions.

Das Institut für Höhere Studien (IHS) wurde im Jahr 1963 von zwei prominenten Exilösterreichern dem Soziologen Paul F. Lazarsfeld und dem Ökonomen Oskar Morgenstern - mit Hilfe der FordStiftung, des Österreichischen Bundesministeriums für Unterricht und der Stadt Wien gegründet und ist somit die erste nachuniversitäre Lehr- und Forschungsstätte für die Sozial- und Wirtschaftswissenschaften in Österreich. Die Reihe Ökonomie bietet Einblick in die Forschungsarbeit der Abteilung für Ökonomie und Finanzwirtschaft und verfolgt das Ziel, abteilungsinterne Diskussionsbeiträge einer breiteren fachinternen Öffentlichkeit zugänglich zu machen. Die inhaltliche Verantwortung für die veröffentlichten Beiträge liegt bei den Autoren und Autorinnen. 


\begin{abstract}
The objective of this paper is to combine a real options framework with portfolio optimization techniques and to apply this new framework to investments in the electricity sector. In particular, a real options model is used to assess the adoption decision of particular technologies under uncertainty. These technologies are coal-fired power plants, biomassfired power plants and onshore wind mills, and they are representative of technologies based on fossil fuels, biomass and renewables, respectively. The return distributions resulting from this analysis are then used as an input to a portfolio optimization, where the measure of risk is the Conditional Value-at-Risk (CVaR).
\end{abstract}

\title{
Keywords
}

Portfolio optimization, CVaR, climate change policy, uncertainty, real options, electricity, investments

\section{JEL Classification}

C61, D81, D92, G11, Q4, Q56, Q58 


\section{Comments}

Ines Fortin, Jaroslava Hlouskova, and Michael Obersteiner gratefully acknowledge financial support from the Austrian National Bank (Jubiläumsfonds Grant No. 11883).

AT IIASA this work was carried out in the framework of the project "Bewertungsmodelle für zukünftige Energiecluster unter Markt-,Technologie- und Politikunsicherheit - Fallstudie Biomasse" funded by FFG (Österreichische Forschungsförderungsgesellschaft), Vienna. Sabine Fuss, Nikolay Khabarov, Michael Obersteiner and Jana Szolgayova are grateful for the financial support of FFG. 


\section{Contents}

1 Introduction 1

2 The Real Options Model 5

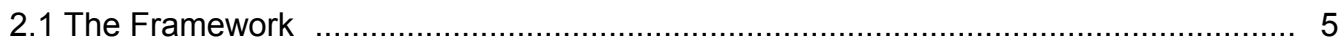

2.2 The Technologies and the Data …………................................................ 9

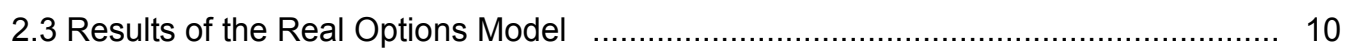

3 CVaR-based Portfolio Optimization 15

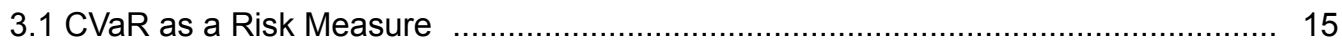

3.2 Portfolio Optimization: Minimizing Risk ....................................................... 17

3.3 Portfolio Optimization: Maximizing Returns ………....................................... 18

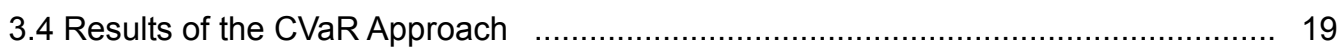

3.5 Mean-variance versus CVaR ………………...................................... 23

4 Conclusion $\quad 27$

Appendix A: Snapshots of Price Distributions for All Scenarios $\quad 29$

Appendix B: Real Options Output for Investing and Switching $\quad 30$

Appendix C: Definitions of Copulas and Related Concepts 33

$\begin{array}{ll}\text { References } & 35\end{array}$ 



\section{Introduction}

Uncertainty about the cause-and-effect relationships of anthropogenic emissions, global warming and a large number of (possibly irreversible) effects impedes effective policy making and poses considerable uncertainties to investors in addition to the common uncertainties originating from fluctuations in input and output prices. If investors cannot be sure about future climate change policy measures, they will typically not invest in environmentally friendly, expensive technologies. Therefore, it is important not only to concentrate on variability in returns from market-driven fluctuations in prices, but also to take into account the uncertainties emanating from the policy making process. In this paper we will focus on investment planning in the electricity sector, since the generation of electricity contributes significantly to total $\mathrm{CO}_{2}$ emissions and has therefore been a major area of concern to policymakers.

The electricity sector is marked not only by uncertainties surrounding investment and production decisions, but also by irreversibility due to the large sunk costs involved in investment in generation equipment and the flexibility to postpone investments to a later point in time during the planning horizon. Therefore, we think that real options modeling is a suitable approach for investment planning. Originally developed for valuing financial options in the seventies (Black and Scholes, 1973, and Merton, 1973), economists soon realized that option pricing also provided considerable insight into decision-making concerning capital investment. Hence the term "real" options. Early frameworks were developed by McDonald and Siegel (1986), Pindyck (1988, 1991, 1993), and Dixit and Pindyck (1994). ${ }^{1}$ The basic idea is that standard investment theory relying on net present value (NPV) calculations generally do not consider the interaction between three important characteristics of investment decisions: the irreversibility of most investments, which implies that a substantial portion of the total investment cost is sunk, the uncertainty surrounding the future cash flows from the investment, which can be affected by e.g. the volatility of output and input prices, and the opportunity of timing the investment flexibly. Regarding the opportunity to defer an investment means that we can assign a value to waiting. In other words, investors gain more information about the uncertainty that surrounds economic decisions as time passes by. Therefore, staying flexible by postponing decisions has an option value if the degree of uncertainty faced is big enough. This value increases if the sunk cost that has to be incurred to launch the project is high, but also in times of larger uncertainty associated with future cost or revenues. In this case it pays off to wait and see how the conditions have changed, especially if they are expected to be rather stable afterwards.

Investment in the electricity sector has been analyzed within real options frameworks before. In the area of short-term planning, this work includes e.g. Tseng and Barz (2002), Hlouskova et al (2005) and Deng and Oren (2003). At the same time, a number of longterm planning frameworks have emerged. A recent example is by Fleten et al (2006), who find that investment in power plants relying on renewable energy sources will be postponed beyond the traditional NPV break even point when a real options approach with stochastic electricity prices is used. With respect to uncertainty from government regulation in the electricity sector, De Jong et al (2004) propose that real options modeling is a valuable method to investigate how fluctuations in future emissions prices affect investment patterns. Also Laurikka (2004), Laurikka and Kojonen (2006), Kiriyama and Suzuki (2004), and Reedman

\footnotetext{
${ }^{1}$ For a comprehensive treatment and overview of both financial and real options theory see Trigeorgis (1996). More advanced and with several applications is Schwartz and Trigeorgis (2001).
} 
et al (2006) deal with the influence of future uncertain emissions trading and with $\mathrm{CO}_{2}$ penalties within a real options setup. In these models the design of emissions trading schemes and the number of allowances that are freely distributed are main features of the overall model.

On the other hand, Fuss et al (2006) focus on the overall effect of uncertainty emanating from climate change policy and the effect of market uncertainty, where the specific form of emissions trading schemes is not an issue. In their framework $\mathrm{CO}_{2}$ prices can be seen as a sort of carbon tax or as the price for an allowance that has to be bought on the carbon market; $\mathrm{CO}_{2}$ prices thus add to the total cost of electricity producers. We use this same framework in the present paper. Sources of uncertainty are the price of $\mathrm{CO}_{2}$ and the price of electricity, which are modeled as stochastic processes. A feature of the model which is disregarded in many other frameworks is the relation between $\mathrm{CO}_{2}$ costs and electricity prices. In our model this is captured by the fact that the increments of the two price processes and thus the price processes themselves are positively correlated. In fact the use of (linear) correlation to describe and model dependence implies a symmetric dependence structure. To capture the intuitively plausible fact that dependence may be higher in times of increasing prices than in times of decreasing prices, more general forms of dependence modeling involving so-called copulas would be appropriate. Solving this is beyond the scope of our paper and will be left for future research.

We use a real options model to find the optimal timing of investing into carbon capture and storage (CCS) modules in the case of coal- and biomass-fired power plants. For renewables the optimal installation time of the plant as such is computed. We find that the wind turbine, the basic coal plant (without CCS) and the basic biomass plant (without CCS) are all built in the first year.

While this optimization is performed by the individual power producer, who wants to set up a new plant, large investors would typically want to invest in a portfolio of technologies rather than concentrate on a single technology or a single chain. The contribution of this paper is to combine portfolio optimization with the results that we derive from our real options framework. In particular, we use the real options model to find the optimal investment strategy and its implied return distributions; the return distributions, then, can be employed as an input into the portfolio optimization. In traditional finance, the standard portfolio optimization procedure is the mean-variance approach introduced by Markowitz (1952), where the portfolio variance is minimized subject to a constraint on the expected return. Risk management in financial institutions, however, has started to employ another measure of risk, the Value-at-Risk (VaR), since it captures extreme - and thus dangerous - events providing information on the tail of a distribution. Also regulatory requirements as specified by the Basel Committee on Banking Supervision $(2003,2006)$ are geared towards the use of VaR. Another risk measure, which is closely related to VaR but offers additional desirable properties like coherence and computational ease, is Conditional Value-at-Risk (CVaR). While VaR is generally better known and more widely employed, we think that CVaR is the more appropriate measure to use. Let us define VaR and CVaR to make clear what we are talking about. According to Rockafellar and Uryasev (2000) the $\beta$-VaR of a portfolio is the lowest amount $\alpha$ such that, with probability $\beta$, the loss will not exceed $\alpha$, whereas the $\beta$-CVaR is the conditional expectation of losses above that amount $\alpha$, where $\beta$ is a specified probability level. ${ }^{2}$

\footnotetext{
${ }^{2}$ This (simple) definition applies only to situations where the loss distribution is continuous. For the
} 
The disadvantages of $\mathrm{VaR}$ as opposed to CVaR relate to both usefulness in risk management and technical properties. VaR does not consider losses exceeding the threshold value while CVaR does, and this information might be useful, in particular in times of financial distress. Further, VaR is only a coherent risk measure in the sense of Artzner et al (1999) if distributions are assumed to be normal; generally, VaR is neither subadditive nor convex. $\mathrm{CVaR}$, on the other hand, is always a coherent risk measure. In addition, the powerful results in Rockafellar and Uryasev $(2000,2002)$ make computational optimization of CVaR readily accessible. Note that, under mild technical restrictions, the minimization of VaR and CVaR and the mean-variance framework yield the same results provided that all underlying distributions are normal. This does not apply if the assumption of normality is violated. We will see that both the univariate distributions and the joint distribution (copula) of the returns, which are the results from our real options procedure, do not seem to be normal in most cases. A more detailed treatment of the difference between VaR and CVaR can be found in Rockafellar and Uryasev (2000). To our knowledge, combining real options with portfolio optimization using CVaR is a new approach which has not been implemented before. Some recent literature has undertaken steps into similar directions, however.

Alesii (2005) uses VaR in combination with real options, but his aims and therefore also his approach are very different from ours. He acknowledges that with a real options approach downside risk is reduced and the distribution of the expanded $\mathrm{NPV}^{3}$ is thus favorably skewed (Trigeorgis, 1996). The aim of his paper is to quantify this impact on risk. To this end he uses an extension of the model by Kulatilaka (1988) to calculate the VaR on the expanded $\mathrm{NPV}$ and the $\mathrm{CFaR}$ (the cash-flow-at-risk in each period of the planning horizon). To be more precise, he first derives expanded NPVs and optimal exercise thresholds for all options with backward induction. Then, with a stochastic, mean-reverting state variable, he conducts a Monte Carlo simulation and uses the simulated time series to compute the cash flows considering the optimal exercise times. Alesii (2005) calls these cash flows "controlled" cash flows and uses them to calculate the expanded NPVs, which converge to the values previously computed recursively. The model results confirm that real options reduce downside risk and reshape the distribution of the expanded NPV positively: Both VaR and CFaR decrease substantially when options are taken into consideration. The conclusion is that real options do not only enhance the value of the expanded NPV compared to the standard NPV, but it also decreases the involved risk. Alesii (2005) therefore uses VaR only as a measure of risk on the distribution of expanded NPV and $\mathrm{CFaR}$ as the risk measure for cash flows in each time period in order to determine the impact of including real options on the variability in NPV and cash flows. In contrast, we use CVaR instead of VaR and we employ it as a risk measure for a portfolio optimization where the distributions resulting from real options modeling are the input rather than the output to the (portfolio) optimization process.

The CVaR approach has been followed by a number of papers dealing with real world risk management, including risk management in the electricity sector. Example of such applications are Unger and Lüthi (2002) and Doege et al (2006); they maximize expected profit of a given power portfolio while restricting overall risk as measured by CVaR. Their model is different from ours in various ways, however. First, the portfolio includes financial assets (contracts) as well as physical assets (production assets), where the latter consist of a num-

discrete case, definitions are more subtle, see Rockafellar and Uryasev (2002).

${ }^{3}$ The expanded NPV differs from the standard NPV by the value of the option that is explicitly taken into account in real options modeling. 
ber of hydro storage/pump plants in the first application and a combination of a base load generator (nuclear power plant) and a peaker (hydro pump storage) in the second one. Time horizons considered are rather short - two weeks and 1 year - with the time unit being one hour. Sources of uncertainty in these models are the electricity price, the demand for electricity and water inflow. Even though the framework used is not explicitly the real options framework, the model is quite similar except for potentially flexible times of investment in the real options framework.

Spangardt et al (2006) present the basic idea of optimizing a power portfolio while constraining risk in terms of CVaR, applying the results of Rockafellar and Uryasev (2000, 2002), and give a survey of related application papers. They, too, do not explicitly suggest a real options framework but their stochastic optimization setup is again quite similar to our real options analysis with the same reservation as above. The application papers referred to, however, turn out - for the most part - to not apply CVaR as a measure of risk; generally risk is taken care of by introducing risk penalties in the objective function, where risk is measured by the standard deviation. One of the applications, which is probably closest to our problem, can be found in Fichtner et al (2002). The authors use the PERSEUS-EVU model ${ }^{4}$ to maximize expected profits by determining the optimal production portfolio, where the planning horizon is 30 years and constraints can be set for emission levels. The paper presents a case study for three different scenarios of $\mathrm{CO}_{2}$ emission limits in Germany. The main results are in line with our results; the production portfolio is significantly changing depending on whether low or high limits are set; where in scenarios with low emission limits wind is gaining most strongly.

Our approach of combining real options with portfolio optimization could be a useful industry investment device. In fact, the results obtained are very intuitive. Still, the numerical results for the individual technologies are supposed to be rather illustrative. The deeper purpose of this paper is to demonstrate the methodology and the usefulness of the new, theoretical approach, and not to give ad hoc investment advice. More specifically, we examine three $\mathrm{CO}_{2}$ price scenarios and we find that there is a trade-off between risk in terms of CVaR and return: Investment does not focus exclusively on the technology with the highest expected return, but diversifies to other technologies in order to keep the associated risk at a minimum. From the low $\mathrm{CO}_{2}$ price scenario going to the high $\mathrm{CO}_{2}$ price scenario, there is a shift from a coal-dominated portfolio to a biomass-dominated portfolio. ${ }^{5}$ Furthermore, if we increase $\beta$, which is the probability level associated with the CVaR, we observe further diversification away from risky technologies, even if they have comparatively high expected returns. The expected return that we specify to be attained at least, $R$, is another factor that influences the risk-return trade-off: The higher we set $R$, the more does the investor tend to increase the share of the technology with the highest expected return at the expense of those that

\footnotetext{
${ }^{4}$ Program Package for Emission Reduction Strategies in Energy Use and Supply - Energieversorgungsunternehmen; the German term means electric utilities.

${ }^{5}$ Wind plays a minor role only, since we have constrained it to make up only $10 \%$ of the portfolio. Due to its low efficiency, it would space-wise not be feasible to set up larger amounts of wind farms. The data in section 2.2 show that you need 1,389 MW to generate the same amount of electricity as the coal-fired power plant, which is only $500 \mathrm{MW}$ big. For a typical unit size of $1.5 \mathrm{MW}$ per wind mill, this makes already 926 wind mills! It stands to question if such a maximum constraint should also be implemented for biomass. In the UK, for instance, there would not be enough capacities to grow all the biomass, even though the technology as such is quite attractive for the UK. However, biomass is thought to be representative of low emission technologies here, so we do not focus on particular country situations and therefore abstract from this constraint.
} 
have a lower CVaR. ${ }^{6}$ So, we can say that the investment focus shifts from lower risk, CVaR, to higher expected returns, i.e. the investor becomes more return-oriented.

The paper will proceed as follows: First, we will sketch out the real options model, which is an extension of Fuss et al (2006). Section 2 will therefore be subdivided into a descriptive, theoretical part, a part presenting the data used and a part explaining the results for the different technologies and technology chains. Section 3 will give an overview of the CVaR portfolio optimization and will present how we use the CVaR to find optimal portfolios based on the distributions from the real options model. Furthermore, section 3 includes a subsection on the importance of using the CVaR in portfolio optimization in case of nonnormal distribution of returns, comparing our approach to the results that one would obtain when using the standard mean-variance portfolio approach. Section 4 concludes.

\section{The Real Options Model}

\subsection{The Framework}

The uncertainties that arise in the context of the electricity generator's investment problem are two-fold. On the one hand, we have uncertainty with respect to output prices. On the other hand, input cost is influenced by fluctuations in the price of $\mathrm{CO}_{2}$ emissions. ${ }^{7}$ The cost of capital is taken to be deterministic, which ignores the occurrence of technological uncertainty. ${ }^{8}$ Moreover, capital is not divisible in this model. That means that the investor has the choice to either invest or to leave the investment opportunity open, i.e. it is not possible to install $500 \mathrm{MW}$ at first and then add another $500 \mathrm{MW}$ later etc. Other prices that are not stochastic are fuel prices, even though we do allow for increases of fossil fuel prices over time. Operations and maintenance $(\mathrm{O} \& \mathrm{M})$ cost and the cost of switching between technologies are deterministic as well. Technological change comes about in the form of decreasing O\&M costs and applies only to immature technologies, such as biomass-fired turbines in our experiments. ${ }^{9}$ Electricity prices follow an $\mathrm{AR}(1)$ price:

$$
\ln P_{t}^{e}=c_{1}+c_{2} \ln P_{t-1}^{e}+\varepsilon_{t}^{e},
$$

where $\varepsilon_{t}^{e} \sim N\left(0,\left(\sigma^{e}\right)^{2}\right)$, with the parameters $\mathrm{c}_{1}=1.655, \mathrm{c}_{2}=0.541$, and $\sigma^{e}=0.092$ based on spot market data from the European Electricity Exchange (EEX). The $\mathrm{CO}_{2}$ prices are modeled based on projections by the MESSAGE model (see Messner and Strubegger (1995) for an overview of the MESSAGE structure). They follow the random walk (RW) with drift.

$$
\Delta \ln P_{t}^{c}=c_{\text {med }}+\varepsilon_{t}^{c},
$$

\footnotetext{
${ }^{6}$ Sometimes the CVaR and variance criteria deliver results that coincide, but this does not necessarily have to be the case as we will see in section 3.5 .

${ }^{7}$ Madlener and Gao (2005) explore the differences in effects when using different policy instruments to support renewable energy. They distinguish between guaranteed feed-in tariffs (such as in Germany) and tradable permits (as suggested by the Kyoto Protocol) and find that subsidies always outperform permits when technological innovation is possible. For our purposes, this distinction between instruments is not that important, which is why we omit it in our analysis.

${ }^{8}$ Uncertainty of technical change in a real options framework has been analyzed by Farzin et al (1998). Another application is by Murto (2006).

${ }^{9}$ Another way of incorporating technological progress has been employed by Kuramboglu et al (2004), who incorporate learning curves for renewable energy into their real options framework. Using data from Turkey, they find that the diffusion of renewable energy technologies will only occur if policies are directed to that cause.
} 
where $\Delta \ln P_{t}^{c}=\ln P_{t}^{c}-\ln P_{t-1}^{c}, \varepsilon_{t}^{c} \sim N\left(0,\left(\sigma^{c}\right)^{2}\right)$, and parameters $\mathrm{c}_{\text {med }}=0.056$ and $\sigma^{c}=$ 0.029. The two noise processes are correlated by the factor $\rho$, which we set equal to 0.7. Figure 1 below illustrates how these price processes look like.
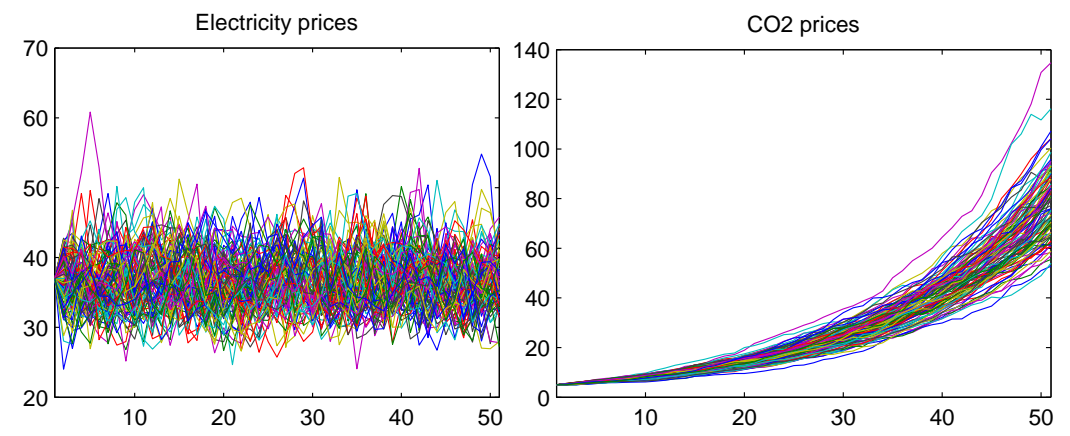

Figure 1: Electricity and $\mathrm{CO}_{2}$ Price Paths (These graphs have years on the x-axis and $€ / \mathrm{MWh}$ and $€ / \mathrm{t}\left(\mathrm{CO}_{2}\right)$ on the y-axis respectively.)

The investor thus faces an optimization problem of maximizing discounted expected future returns over all possible future actions under uncertainty about future prices. The problem can be formulated as an optimal control problem with state and control variables. Let $x_{t}$ denote the state that the system is currently in, i.e. it tells you whether the basic plant, the CCS module or both have been built and whether the CCS module is currently running. The starting value of $x_{t}$ is known. Which part of the total plant is currently active is described by the variable $m_{t}$, where $m_{t}$ is part of the state $x_{t}$. If no plant is operating, $m_{t}=0$; if the basic plant without CCS is operating, $m_{t}=1$; and if the plant with additional CCS is operating, $m_{t}=2$. Only at $t=0$, is $m_{t}=0$. Furthermore, let $a_{t}$ be the action, i.e. the control, which the decision-maker chooses to undertake in year $t$. Possible actions $a_{t}$ include (i) building the basic power plant, (ii) building the power plant including the CCS module, (iii) adding the CCS module, (iv) switching the CCS module off, (v) switching the CCS module on, and (vi) doing nothing. Whether an action is feasible at time $t$ depends on the state at time $t$. The CCS module can only be switched on, for example, if it has been built already and if it is currently not running. The set of feasible actions at time $t$ is denoted $A\left(x_{t}\right)$, and only feasible actions $a_{t} \in A\left(x_{t}\right)$ can be performed. The state in the next period is then determined by the current period's state $x_{t}$ and the current period's action $a_{t}$, formally $x_{t+1} \in \Gamma\left(x_{t}, a_{t}\right)$.

As described by Equations (2.1) and (2.2), prices for electricity and $\mathrm{CO}_{2}$ follow stochastic processes. The starting values for these processes are known with certainty. The investor can thus solve the optimal control problem of maximizing discounted expected profits,

$$
\max _{\left\{a_{t}\right\}_{t=0}^{T}} \sum_{t=0}^{T} \frac{1}{(1+\gamma)^{t}} \mathbb{E}\left[\pi\left(x_{t}, a_{t}, P_{t}^{e}, P_{t}^{c}\right)\right],
$$

subject to $a_{t} \in A\left(x_{t}\right)$ and $x_{t+1} \in \Gamma\left(x_{t}, a_{t}\right)$, with $x_{0}, P_{0}^{e}$ and $P_{0}^{c}$ known and $\gamma$ the discount rate. The profit $\pi(\cdot)$ consists of income from electricity and heat less the cost of fuel, the payments for $\mathrm{CO}_{2}$ emissions, O\&M costs and costs associated with the action, $c\left(a_{t}\right)$. The production function is of the Leontieff type, which means that coefficients are fixed. Output is therefore the product of the rate of efficiency and the amount of the fuel used. Since we assume that all 
electricity (and heat), which is generated, can be sold inelastically, ${ }^{10}$ the installed plant will be run continuously, thereby producing a fixed amount of output for a fixed amount of input per year. Any change in investment behavior, therefore, must be due to price uncertainty.

The immediate profit can be calculated as

$$
\begin{aligned}
\pi\left(x_{t}, a_{t}, P_{t}^{e}, P_{t}^{c}\right) & =q^{e}\left(m_{t}\right) P_{t}^{e}+q^{h}\left(m_{t}\right) P^{h}-q^{c}\left(m_{t}\right) P_{t}^{c} \\
& -q^{f}\left(m_{t}\right) P^{f}-O C\left(m_{t}\right)-c\left(a_{t}\right),
\end{aligned}
$$

where $P^{h}$ is the price of heat, $P^{f}$ is the price of the fuel, which will obviously be zero for the renewable energy carriers such as wind, $O C$ is the operational cost per year, $q^{e}, q^{h}, q^{c}$ and $q^{f}$ refer to annual quantities of electricity, heat (where it is important to note that renewable energy carriers do not produce heat as a byproduct of electricity generation), carbon dioxide and fuel, respectively, and $m_{t}$ denotes the type of power plant that is operational at time $t$ (no plant, plant without CCS, plant with CCS). The total discounted income will be divided by total discounted cost, so that we ultimately use returns instead of profits in our CVaR optimization.

It is important to take note of the tradeoffs implied by this profit equation: while the amount of electricity generated will be lower and the operational cost higher if a CCS module is added, the cost arising from carbon payments will be lower as well, since $\mathrm{CO}_{2}$ emissions decrease. In order to give the reader a feeling of how significant the difference in carbon emissions is, please consider that in our case the coal-fired power plant without CCS emits 2,155 kt $\mathrm{CO}_{2} / \mathrm{yr}$, whereas the one with $\mathrm{CCS}$ produces only $292 \mathrm{kt} \mathrm{CO}_{2} / \mathrm{yr}$ for the same amount of combusted coal (see Table 1). The "clean" power plant thus emits more than seven times less carbon dioxide than the "dirty" power plant. Even though investors will typically install only the dirty power plant in the beginning (because of the significant extra cost in terms of capital when adding the sequestration CCS module), if initial carbon prices are low, they may want to add CCS when carbon prices rise and render instalment of the CCS module more attractive. In our practical application, the focus will therefore be on the timing of installing the CCS module. Since wind mills do not emit carbon dioxide, there is no need for a CCS module and thus there is no technology chain. $m_{t}$ can therefore only assume values 0 (nothing is operational, which only happens in year 0 ) and 1 (the wind mill is assumed to be operational from year 1 on).

Furthermore, we assume that installing a power plant implies its immediate use and that there is no delay in the realization of the payoffs, that is we abstract from differences in construction times. ${ }^{11}$

As the investor's problem can be formulated as an optimal control problem and restated in a recursive functional form, we employ dynamic programming ${ }^{12}$ to find the optimal control for the above model. Stochastic dynamic programming is useful when one faces sequential

\footnotetext{
${ }^{10}$ This assumption can be justified by acknowledging that distributors will engage into output contracts with generators, specifying amounts of electricity and heat that will be bought off for a prolonged period of time.

${ }^{11}$ Construction times could be included easily, but we leave them aside for the moment, since this is not our focus and would not change the results qualitatively (if we expand the planning horizon), unless lead times would be dramatically different between different types of plants. Chladná et al (2004), who use a similar setup to investigate the pulp and paper sector, also claim that disregarding this aspect has no impact on the interpretation of the simulation results (Chladná et al (2004), pages 22-23).

${ }^{12}$ Dynamic programming was developed in the early fifties by a mathematician called R. Bellman, hence the expression Bellman equation encountered later in this paper.
} 
decision-making, where intermediate stages are not known with certainty. A necessary condition for this approach is that the Markov property holds, i.e. that the optimal action for the next period only depends on the current state that the decision-maker is in, and not on past decisions that have brought him/her there. This requirement holds for our problem. In particular, dynamic programming - stochastic or deterministic - starts from the "back" of the problem and solves for the optimal decisions recursively. ${ }^{13}$ In our case of electricity capacity planning we will be going through all possible values of the value function depending on all the possible states that the decision-maker can be in depending upon all realizations of prices and thereby determine the optimal action in each stage. In mathematical terms, we formulate the value function corresponding to the maximization problem (2.3), which then has to be maximized by determining the optimal investment strategy $\left\{a_{t}\right\}_{t=1}^{T}$, where $T$ is the planning horizon. The value function, also called Bellman equation, takes the following form

$$
V\left(x_{t}, P_{t}^{e}, P_{t}^{c}\right)=\max _{a_{t} \in A\left(x_{t}\right)}\left\{\pi\left(x_{t}, a_{t}, P_{t}^{e}, P_{t}^{c}\right)+\frac{1}{(1+\gamma)} \mathbb{E}\left(V\left(x_{t+1}, P_{t+1}^{e}, P_{t+1}^{c}\right) \mid x_{t}, P_{t}^{e}, P_{t}^{c}\right)\right\},
$$

where $x_{t+1} \in \Gamma\left(x_{t}, a_{t}\right)$ and $\gamma$ is the discount rate. The value function can be decomposed into the immediate profit, $\pi\left(x_{t}, a_{t}, P_{t}^{e}, P_{t}^{c}\right)$, which the producer receives upon investment, and the discounted expected continuation value $1 /(1+\gamma) \mathbb{E}\left(V\left(x_{t+1}, P_{t+1}^{e}, P_{t+1}^{c}\right) \mid x_{t}, P_{t}^{e}, P_{t}^{c}\right)$. It is important to note that the continuation term is evaluated for the specific state the producer is in, which changes according to the actions he/she undertakes. States which are not feasible will not be considered.

There are different methods of computing the expected value of the value function, $\mathbb{E}(V(\cdot))$. As the type of stochasticity is known, the term can be computed by the means of partial differential equations following the steps in Dixit and Pindyck (1994). The derivations for this approach can be found in Fuss et al (2006), where a similar model is used. Although the method of using partial differential equations along with appropriate boundary conditions is the most elegant way mathematically, this approach has proved - once numerically implemented - to be inflexible to variations and extensions and computationally intensive when using a finer grid. ${ }^{14}$ With respect to the latter problem, the tradeoff between the stability of the numerical scheme and the precision of the final results turns out to be very delicate, which is why we resort to solving the problem at hand with Monte Carlo simulations. The advantage of the Monte Carlo approach is that it is relatively easy to extend. Also, it has proven to remain efficient in this framework for a rather high degree of complexity and delivers the same results as the partial differential equations approach. In summary therefore, we use backward dynamic programming with forward-moving Monte Carlo simulation. ${ }^{15}$ Of the work reviewed in the introduction, there are various studies that also use Monte Carlo simulation for real options modeling in the electricity sector, e.g. Tseng and Barz (2002),

\footnotetext{
${ }^{13}$ This is equivalent to backward optimization procedures that each of us solves more or less subconsciously in everyday situations such as planning a journey to arrive at your destination on time.

${ }^{14}$ The differential equation needs to be approximated by difference equations which can be solved numerically. This is achieved by constructing a grid, which discretizes the time-price domain. For precise solutions, a fine price grid is necessary that requires smaller time steps to guarantee numerical stability. As a result, the dimension of the problem rises considerably and requires extensive computer resources.

${ }^{15}$ There is also a third method to move forward and find the optimum decisions. This involves binomial lattice frameworks or binomial decision trees. Even though these are very intuitive and rather flexible when introducing multiple uncertainties and concurrent options, they also tend to get computationally very intensive and therefore not very suitable for our purposes.
} 
who focus on short term generation, and Laurrika and Koljonen (2006), who adopt long term planning horizons.

\subsection{The Technologies and the Data}

The technologies that we are focussing on in our analysis are coal with the possibility of adding a CCS module, biomass also with the CCS option, and (onshore) wind. These technologies stand representative of fossil fuel technologies (coal), technologies with less emissions (biomass) and zero-emission renewables (wind). We are using data from the International Energy Agency/OECD. The data for biomass have been taken from Leduc et al (forthcoming). ${ }^{16}$ They are assembled in Tables 1 and 2 below. Note that electricity output of the three plants (without CCS) is the same, so they are similar in size.

\begin{tabular}{lrlll}
\hline Parameters & & Coal & Coal + CCS & Wind \\
\hline Electricity Output & {$[\mathrm{TWh} / \mathrm{yr}]$} & 3,285 & 2,642 & 3,285 \\
$\mathrm{CO}_{2}$ Emissions & {$[\mathrm{kt} \mathrm{CO} / \mathrm{yr}]$} & 2,155 & 292 & 0 \\
Fuel Consumption & {$[\mathrm{TJ} / \mathrm{yr}]$} & 23,188 & 23,188 & 0 \\
Fuel Cost & {$[€ / \mathrm{TJ}]$} & 1,970 & 1,970 & 0 \\
O\&M Fixed Cost & {$[1,000 € / \mathrm{yr}]$} & 40,250 & 48,450 & 19,667 \\
Installed Capacity & {$[\mathrm{MW}]$} & 500 & 402.17 & 1,389 \\
Power Efficiency & {$[\%]$} & 46 & 37 & 27 \\
Heat Efficiency & {$[\%]$} & 34 & 34 & 0 \\
Heat Price & {$[€ / \mathrm{TJ}]$} & 11,347 & 11,347 & - \\
Capital Cost & & & & \\
Common Parts & {$[1,000 €]$} & 686,500 & 686,500 & - \\
Cost CCS Module & {$[1,000 €]$} & & 137,946 & - \\
Total Capital Cost & {$[1,000 €]$} & 686,500 & 824,446 & $1,042,735$ \\
\hline
\end{tabular}

Table 1: Power Plant Data for Coal and Wind (Source: "Projected Costs of Generating Electricity 2005 Update", IEA/OECD, 2005)

In addition, coal prices are assumed to be rising according to the predictions of the same source. We have taken German coal prices, from 2010-2060. The starting prices can be found in Table 1. The biomass fuel prices are from Leduc et al (forthcoming).

The exorbitantly high O\&M costs of the biomass plant is due to the relative immaturity of the technology. With only slight rates of technical change, these costs will drop until they eventually reach about the same magnitude as coal, which is technically very similar in its operation and maintenance. We assume to see such technological progress happen in our model. Another peculiarity of the biomass plant is the negative amount of emissions indicated in the Table. Without the CCS module, biomass already generates zero emissions. This is not really true, since the biomass plant does generate emissions. However biomassbased electricity production requires the plantation of extra trees or other biomass, which will extract $\mathrm{CO}_{2}$ from the atmosphere on top of what is extracted through existing trees and biomass. Therefore, the emissions from biomass-generated electricity are treated as zero, even

\footnotetext{
${ }^{16}$ These had to be scaled up to make them comparable with coal, otherwise the output would have been too low.
} 


\begin{tabular}{lrll}
\hline Parameters & & Bio & Bio $+C C S$ \\
\hline Electricity Output & {$[\mathrm{TWh} / \mathrm{yr}]$} & 3,285 & 2,628 \\
$\mathrm{CO}_{2}$ Emissions & {$[\mathrm{kt} \mathrm{CO} / \mathrm{yr}]$} & 0 & $-2,691$ \\
Fuel Consumption & {$[\mathrm{TJ} / \mathrm{yr}]$} & 29,565 & 29,565 \\
Fuel Cost & {$[€ / \mathrm{TJ}]$} & 1,692 & 1,692 \\
O\&M Fixed Cost & {$[1,000 € / \mathrm{yr}]$} & 77,000 & 91,568 \\
Installed Capacity & {$[\mathrm{MW}]$} & 500 & 400 \\
Power Efficiency & {$[\%]$} & 40 & 32 \\
Heat Efficiency & {$[\%]$} & 16 & 16 \\
Heat Price & {$[€ / \mathrm{TJ}]$} & 11,347 & 11,347 \\
Capital Cost & & & \\
Common Parts & {$[1,000 €]$} & 402,029 & 402,029 \\
Cost CCS Module & {$[1,000 €]$} & & 320,333 \\
Total Capital Cost & {$[1,000 €]$} & 402,029 & 722,362 \\
\hline
\end{tabular}

Table 2: Power Plant Data for Biomass (Source: Leduc et al, forthcoming)

though the process will be more complicated in reality: producers would first pay out the $\mathrm{CO}_{2}$ charges and receive the subsidies or allowances for their positive $\mathrm{CO}_{2}$ externality only later. That the $\mathrm{CO}_{2}$ charges and the subsidies/allowances exactly cancel out is an assumption. With an in-built CCS module, the emissions are reduced, but still the same amount of emissions is subtracted as before, so they will turn negative once everything is accounted for. The discount rate is $4 \%$ and the planning horizon is fifty years. All calculations are based on 10,000 simulations.

\subsection{Results of the Real Options Model}

The real options model is run for three technologies - coal with the possibility to add CCS, biomass with the possibility to add CCS and wind - and for three $\mathrm{CO}_{2}$ price scenarios. The scenario where $\mathrm{CO}_{2}$ prices show an average yearly price increase ${ }^{17}$ of $c_{\text {med }}=5.64 \%$ is called the "medium (normal) $\mathrm{CO}_{2}$ price scenario" or scenario 2. This is the price process described above. To analyze the impact of $\mathrm{CO}_{2}$ prices on investment planning we consider two additional scenarios, one with particularly high $\mathrm{CO}_{2}$ prices (scenario 1 ) and one with particularly low $\mathrm{CO}_{2}$ prices (scenario 3). In the first scenario, the average yearly price increase is $1.2 \mathrm{c}_{\text {med }}$, i.e. $20 \%$ higher than in the normal scenario, in the third scenario the average yearly price increase is $0.5 \mathrm{c}_{m e d}$, i.e. half the increase of the normal scenario. The variance of the price process is not changed across scenarios, that is $\sigma^{c}=0.029$ in all three scenarios.

In the following we present numbers and graphs, which are based on the optimal investment strategy for the stochastic control problem stated in (2.3) for a given technology and scenario. As an overall assessment device we calculate the return of investment by taking total discounted income over total discounted cost. Table 3 displays expected return, variance, $\mathrm{VaR}$ and $\mathrm{CVaR}$ for all three technologies across all three scenarios, Table 4 shows the corresponding correlation matrices. We will present the frequency distribution of the return in the first graph of a panel of four graphs (Figures 2 and 3). The second graph shows the

\footnotetext{
${ }^{17}$ To be precise, if we talk about price increases we mean logarithmic price differences.
} 
year, in which the CCS module should be added to the basic power plant. The remaining two graphs show the year, in which it is optimal to switch off the CCS module and in which it is optimal to switch it on again. These graphs actually show frequency distributions of the optimal year when the respective action should be taken. Note that it is never optimal to install the CCS module in the beginning of the planning horizon, since initial $\mathrm{CO}_{2}$ prices are too low to trigger such an extra investment immediately. For the third technology, wind power plants, there is no CCS module to add (since there are no $\mathrm{CO}_{2}$ emissions) and thus the reader can refer to Figure 4 for the return distribution. Figures 2 and 3 show the graphs described for the coal and biomass technologies in the normal $\mathrm{CO}_{2}$ price scenario. The return distributions for all scenarios are displayed in Figure 4 and the corresponding Figures for investment and switching frequencies across all scenarios can be found in Appendix B.
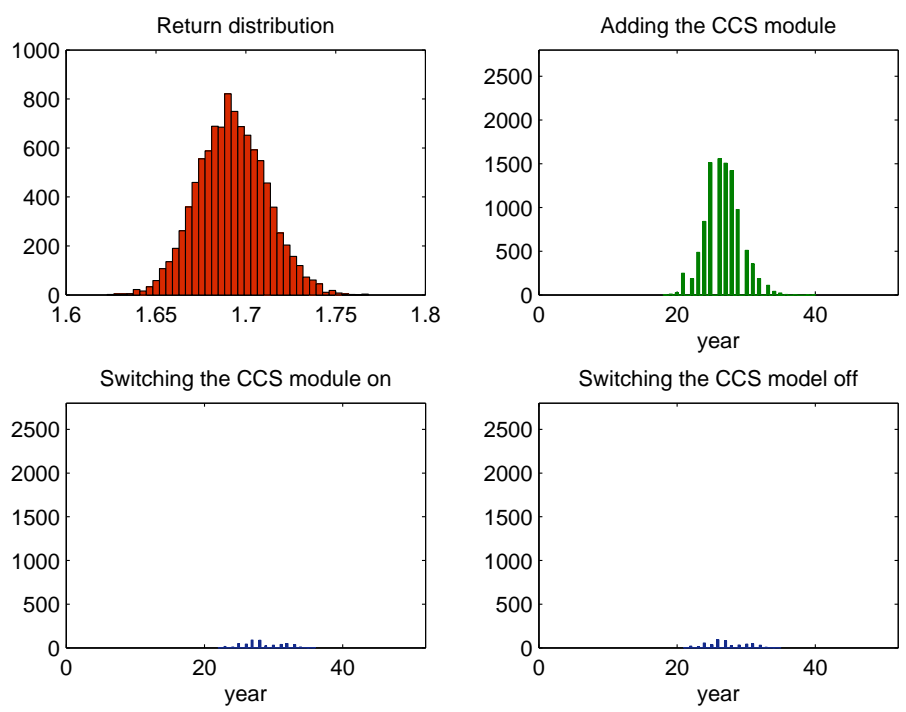

Figure 2: Return and Investment Frequency Distribution for Coal (Graph 1: The return distribution peaks at 1.69. Graph 2: CCS module is added around year 25 most of the time. Graphs 3 and 4: Only a slight occurrence of switching the CCS module on and off.)

Figure 2 shows that for the coal technology it is optimal to add the CCS module between year 20 and 35. The return distribution shows a lower expected return than for biomass and wind in the normal $\mathrm{CO}_{2}$ price scenario. Figure 4 shows that this gets even worse in the high $\mathrm{CO}_{2}$ price scenario. Only in the low $\mathrm{CO}_{2}$ price scenario does coal show a higher expected return than biomass, whereas it is still less profitable than wind. This can be verified in Table 3. Furthermore, Table 3 shows that coal is the least risky plant in scenario 3, while it has the most unattractive -CVaR in scenario 1 , where $\mathrm{CO}_{2}$ prices are high. The probability that the CCS module is switched off after it has been installed is quite low for coal-fired power plants. So there seems to be relatively low uncertainty about the optimal time when the CCS module should be added; it is installed as soon as the average $\mathrm{CO}_{2}$ price rises above a certain level (where the variability of the price process seems to be too low to trigger lots of switches). As can be seen in Figures B.1 and B.3 in Appendix B, the optimal time of adding CCS is clearer in scenario 1 (there are in fact no off-switches after it has been installed), while in scenario 3 
the $\mathrm{CO}_{2}$ price is too low to trigger investment in the CCS module most of the time.
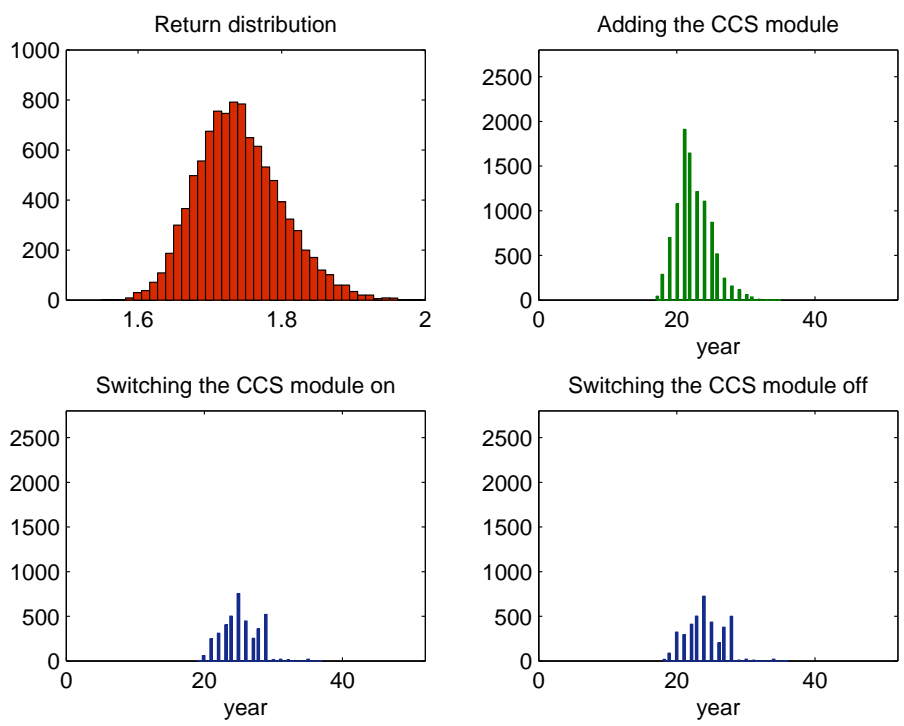

Figure 3: Return and Investment Frequency Distribution for Biomass (Graph 1: The return distribution peaks at 1.72. Graph 2: CCS module is added around year 21 most of the time. Graphs 3 and 4: Only a slight occurrence of switching the CCS module on and off, but the frequency is higher than for coal.)

Figure 3 shows a slightly different picture for the biomass technology. The CCS module is first built between year 18 and 30 - some years earlier than in the coal technology - and there are significantly more switches before the CCS module is permanently running. The reason for this is that the biomass plant is more heavily influenced by fluctuations in the $\mathrm{CO}_{2}$ price than coal due to the comparatively larger reduction in $\mathrm{CO}_{2}$ emissions upon CCS installment (and hence larger impact in the cost induced by $\mathrm{CO}_{2}$ emissions). ${ }^{18}$ Biomass is the least risky option in scenario 1 in terms of CVaR as can be seen from Table $3 .{ }^{19}$

For wind, the optimization only concerns the date of investment of the plant as such, since the are no "add-ons" as in the case of coal and biomass. Furthermore, the wind plant does not suffer from the volatility of the $\mathrm{CO}_{2}$ price, since it does not emit $\mathrm{CO}_{2}$ in the first place. The return distribution displayed in Figure 4 is therefore only based on the simulations of the electricity price. The result of the fact that wind does not have the extra costs imposed by $\mathrm{CO}_{2}$ regulations is that the returns for wind are higher than those for coal and biomass. Also, the expected return, its $-\mathrm{CVaR}$ and the variance are the same for all scenarios.

Let us now turn to the statistical properties of the return distributions. As suggested in the introduction, the assumption of normal distributions for the individual risk factors (technologies) makes variance, $\mathrm{VaR}$ and $\mathrm{CVaR}$ minimization, under some mild technical assumptions, equivalent. We will argue, however, that the assumption of joint normality is

\footnotetext{
${ }^{18}$ In fact, for biomass this will be income due to the negative $\mathrm{CO}_{2}$ emissions.

${ }^{19}$ Note that here the risk analysis would not coincide for the risk measures in terms of CVaR and variance. Section 3.5 will provide a more detailed analysis of the differences between the mean-variance approach and $\mathrm{CVaR}$ as a risk measure.
} 


\begin{tabular}{l|rrrr}
\hline & Exp. return & Variance $\%$ & - VaR & - CVaR \\
\hline Scenario 1 & & & & \\
Coal & 1.658 & 0.034 & 1.628 & 1.621 \\
Biomass & 1.861 & 0.615 & 1.743 & 1.717 \\
Wind & 1.815 & 0.300 & 1.727 & 1.705 \\
\hline Scenario 2 & & & & \\
Coal & 1.692 & 0.037 & 1.661 & 1.654 \\
Biomass & 1.741 & 0.351 & 1.652 & 1.633 \\
Wind & 1.815 & 0.300 & 1.727 & 1.705 \\
\hline Scenario 3 & & & & \\
Coal & 1.788 & 0.045 & 1.754 & 1.745 \\
Biomass & 1.668 & 0.096 & 1.618 & 1.605 \\
Wind & 1.815 & 0.300 & 1.727 & 1.705 \\
\hline
\end{tabular}

Table 3: Expected Returns, Variances, CVaR and VaR of the Coal-fired Power Plant, the Biomass-fired Power Plant and Onshore Wind Mills for the Three Scenarios and $\beta=95 \%$ (Scenario 1: high $\mathrm{CO}_{2}$ prices; scenario 2: medium $\mathrm{CO}_{2}$ prices; scenario 3: low $\mathrm{CO}_{2}$ prices.)

\begin{tabular}{l|ccc}
\hline & Coal & Biomass & Wind \\
\hline Scenario 1 & & & \\
Coal & 1.000 & 0.305 & 0.738 \\
Biomass & 0.305 & 1.000 & 0.836 \\
Wind & 0.738 & 0.836 & 1.000 \\
\hline Scenario 2 & & & \\
Coal & 1.000 & 0.474 & 0.783 \\
Biomass & 0.474 & 1.000 & 0.882 \\
Wind & 0.783 & 0.882 & 1.000 \\
\hline Scenario 3 & & & \\
Coal & 1.000 & 0.506 & 0.469 \\
Biomass & 0.506 & 1.000 & 0.989 \\
Wind & 0.469 & 0.989 & 1.000 \\
\hline
\end{tabular}

Table 4: Correlation Matrices for the Three Scenarios (Scenario 1: high $\mathrm{CO}_{2}$ prices; scenario 2: medium $\mathrm{CO}_{2}$ prices; scenario 3: low $\mathrm{CO}_{2}$ prices.)

not justified in our application. Note that the assumption of marginal normal distributions does not necessarily guarantee a joint normal distribution. We need to examine all marginal distributions and the joint distribution, where we make use of the so-called copula. ${ }^{20}$ The copula is that part of the joint distribution function, which captures everything describing dependence (after factoring out the marginal distributions). In fact, already a first inspection of the marginal return distributions (see Figure 4) suggests that they are not normal. In considering the copula, we look at the three (bivariate) distribution functions, and thus at

\footnotetext{
${ }^{20}$ In fact, marginal normality suffices if one looks at the sum of normally distributed random variables. If one could verify normality for each return distribution, copulas need not be considered. This is not the case here, however; see also Section 3.5.
} 
the three copulas, describing coal/biomass, coal/wind and biomass/wind dependence.

Formally, let $F$ be an two-dimensional distribution function of random variables $X$ and $Y$ with marginal distribution functions $F_{x}$ and $F_{y}$. Then,

$$
F(x, y)=C\left(F_{x}(x), F_{y}(y)\right)
$$

where, under some technical conditions, $C$ is unique. For more details refer to Appendix C. One specific copula, which is implicitly used all the time, is the normal copula; this is the copula implied by the joint normal distribution. One property of the normal copula is that it displays symmetric dependence, that is, dependence in the lower and upper tail of the distribution is the same. One way of testing normality, or more precisely, symmetric dependence, is to consider a copula which allows for potentially different lower and upper tail dependence and to check whether the restriction of equal lower and upper tail dependence can be rejected. Loosely speaking, lower tail dependence $\lambda_{L}$ describes how two random variables move together in the lower tail of the distribution. Upper tail dependence $\lambda_{U}$ describes how two random variables move together in the upper tail of the distribution. A higher $\lambda_{L}\left(\lambda_{U}\right)$ obviously means a higher degree of dependence in the lower (upper) tail. For a more formal definition see Appendix C. If our test showed that the dependence between individual returns is not symmetric, the implied joint distribution could not be the normal one. And hence the variance, VaR and CVaR minimization would not necessarily yield the same results.

In order to conduct such a test we need to consider a fairly flexible copula allowing for different lower and upper tail dependence. The Clayton and the Gumbel copula, two widely used one-parametric Archimedean copulas, are too restrictive in the sense that they allow of only lower (Clayton) or only upper (Gumbel) positive tail dependence, while the other tail dependence is always zero. This - necessarily asymmetric - type of copula is not suitable for our application and thus we decided to use the two-parametric BB1 copula. The BB1 copula allows for asymmetric and symmetric dependence and it nests the popular Clayton and the Gumbel copulas. Its parametric form is

$$
C(u, v)=\left\{1+\left[\left(u^{-\theta}-1\right)^{\delta}+\left(v^{-\theta}-1\right)^{\delta}\right]^{1 / \delta}\right\}^{-1 / \theta},
$$

where $\theta>0$ and $\delta \geq 1$. Details can be found in Appendix C. We estimate the BB1 copula through maximum likelihood, where we take empirical distributions for the marginal returns. Then we restrict this same copula in the sense that lower tail dependence equals upper tail dependence and conduct a likelihood ratio test. In nearly all cases the null hypothesis of equal lower and upper tail dependence $\left(H_{0}: \lambda_{L}=\lambda_{U}\right)$ can be rejected at the $5 \%$ significance level. Table 5 shows the results for all technologies in the three different scenarios. In all cases (except two) the assumption of symmetric dependence can be rejected; in these cases, the assumption of joint normality would not be appropriate. ${ }^{21}$

Interestingly, for biomass/wind a larger degree of dependence is prevalent in the lower tail of the distribution (in all scenarios); the difference between the lower and upper tail dependence is small, however. On the other hand a larger degree of dependence seems to be present in the upper part tail of the distribution for coal/wind and coal/biomass (in all scenarios). Interpreting these results is not straightforward, since the underlying model is complex and generally includes two stochastic processes, the electricity and the $\mathrm{CO}_{2}$ price process. Assuming that, ceteris paribus, higher returns are triggered by higher income through

\footnotetext{
${ }^{21}$ Note that the dependence between biomass and wind in scenario 3 is too large to estimate the copula parameters. The linear correlation is 0.99 , as can be seen from Table 4 .
} 


\begin{tabular}{lccc}
\hline & Coal/Biomass & Coal/Wind & Biomass/Wind \\
\hline Scenario 1 & & & \\
$\hat{\theta}$ & 0.2370 & 0.4668 & 0.6632 \\
$\hat{\delta}$ & 1.0977 & 1.6373 & 1.9316 \\
$l l$ & 484.06 & 3811.66 & 5932.10 \\
$\hat{\lambda}_{L}$ & 0.0696 & 0.4037 & 0.5821 \\
$\hat{\lambda}_{U}$ & 0.1197 & 0.4729 & 0.5683 \\
$\hat{\tau}$ & 0.1855 & 0.5048 & 0.6112 \\
$H_{0}: \lambda_{L}=\lambda_{U}$ & rej & rej & not rej \\
\hline Scenario 2 & & & \\
$\hat{\theta}$ & 0.3393 & 0.4658 & 0.8090 \\
$\hat{\delta}$ & 1.2150 & 1.8000 & 2.1773 \\
$l l$ & 1240.42 & 4617.59 & 7542.44 \\
$\hat{\lambda}_{L}$ & 0.1861 & 0.4375 & 0.6747 \\
$\hat{\lambda}_{U}$ & 0.2309 & 0.5303 & 0.6251 \\
$\hat{\tau}$ & 0.2963 & 0.5494 & 0.6730 \\
$H_{0}: \lambda_{L}=\lambda_{U}$ & not rej & rej & rej \\
\hline Scenario 3 & & & \\
$\hat{\theta}$ & 0.2165 & 0.2416 & - \\
$\hat{\delta}$ & 1.3012 & 1.2473 & - \\
$l l$ & 1343.50 & 1136.72 & - \\
$\hat{\lambda}_{L}$ & 0.0854 & 0.1003 & - \\
$\hat{\lambda}_{U}$ & 0.2965 & 0.2568 & - \\
$\hat{\tau}$ & 0.3065 & 0.2847 & - \\
$H_{0}: \lambda_{L}=\lambda_{U}$ & rej & rej & - \\
\hline & & & \\
\hline & & & \\
\hline & & & \\
\hline
\end{tabular}

Table 5: Copula Results for Return Distributions (The bivariate BB1 copula with parameters $\theta$ and $\delta$ is estimated. We report parameter estimates, the log-likelihood $(l l)$, and implied lower $\left(\lambda_{L}\right)$ and upper $\left(\lambda_{L}\right)$ tail dependence and Kendall's rank correlation tau $(\tau)$. We additionally provide the results of a likelihood ratio test, where the restricted copula is the symmetric $\mathrm{BB} 1$ in the sense that lower tail dependence is equal to upper tail dependence.)

higher electricity prices, the results indicate that for coal/wind and coal/biomass the observed dependence is higher in increasing electricity markets, while for biomass/wind it is higher in decreasing electricity markets. The term "increasing markets" means that prices in these markets increase; the same applies to decreasing markets. To be able to provide a more subtle picture of the impact of the two sources of uncertainty (electricity and $\mathrm{CO}_{2}$ prices), a more detailed analysis is required.

\section{CVaR-based Portfolio Optimization}

\subsection{CVaR as a Risk Measure}

Making an investment decision involves taking a certain admissible level of risk. Usually a criterion to discern the risk related to different investment strategies - a specific risk measure 

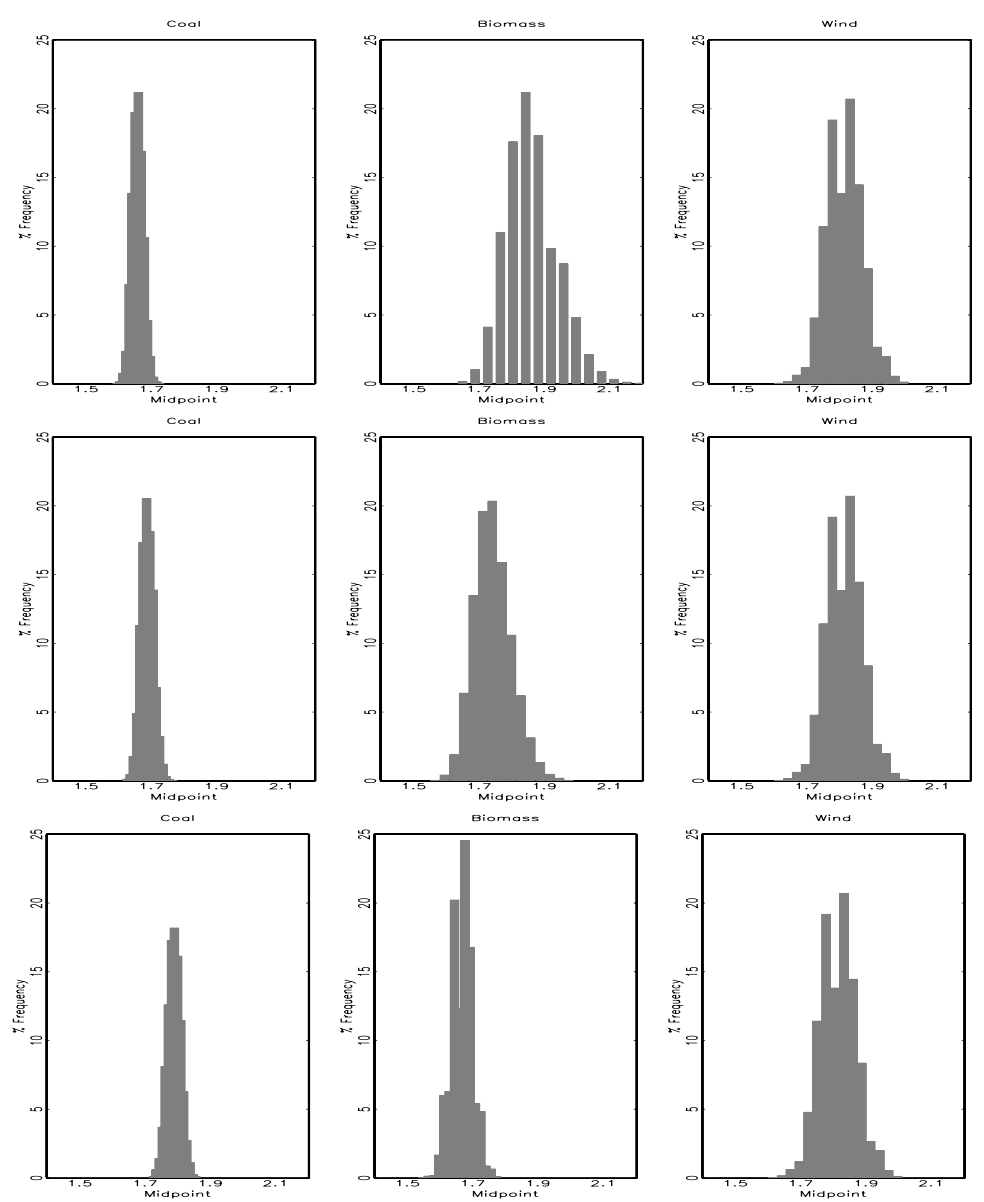

Figure 4: Return Distributions of Coal, Biomass and Wind Technologies (The top row shows returns for high $\mathrm{CO}_{2}$ prices, the middle row shows returns for medium $\mathrm{CO}_{2}$ prices, the bottom row shows returns for low $\mathrm{CO}_{2}$ prices. The number of simulations is $10^{4}$.)

- is needed to select an appropriate investment strategy. We suggest using CVaR as the risk measure in our investment model in the electricity sector. Here is a short discussion regarding the suggested approach.

Value-at-Risk (VaR) is a widely used measure of risk and it is part of the Basel II methodology of the international standards for measuring the adequacy of a bank's capital, as stated in the introduction. However, VaR has several disadvantages, as for example discussed in the papers by Rockafellar and Uryasev (2000) and Palmquist et al (2002). The issue of coherency of risk measures and VaR is debated in the papers by Arztner et al (1997) and Rockafellar and Uryasev (2002). Contributions dealing with CVaR applications have also grown rapidly within the past few years. CVaR is becoming increasingly popular in various areas of risk management including energy risk management (Doege et al, 2006), crop insurance (Schnitkey et al, 2004 and Liu et al, 2006), power portfolio optimization (Unger and Lüthi, 2002), hedge funds applications (Krokhmal et al, 2003), pension funds management (Bogentoft et al, 2001), and multi-currency asset allocations (Topaloglou et al, 2002).

CVaR offers a number of improvements over VaR; first it may be considered as an extension 
of this commonly used risk measure. CVaR provides a sort of approximation of VaR in the sense that it is an upper bound of VaR. Hence minimizing CVaR instead of VaR in portfolio optimization may be considered a more "conservative" approach. Another advantage of using $\mathrm{CVaR}$ as a risk measure is that $\mathrm{CVaR}$ provides the decision maker with more information than VaR. The latter indicates the maximum value of losses, which an investor incurs given some pre-defined probability (most probable event); it does not reveal anything about how big the losses could be in case the less probable event occurs, while CVaR does. CVaR thus provides the investor with valuable information about which losses he/she should expect in the "low probability" case. From this point of view, CVaR offers potential advantages to hedge investments into funds or industry sectors regulated by VaR restrictions on their assets risk. An important property of $\mathrm{CVaR}$ which matters in applications is that CVaR is relatively easy to calculate. Basically, the calculation of CVaR can be reduced to a linear programming problem which may effectively be solved using a broad range of applied software available on the market.

We will define CVaR according to the paper by Rockafellar and Uryasev (2000). Let $f(x, y)$ be the loss function depending on the investment strategy $x \in \mathbb{R}^{n}$ and the random vector $y \in \mathbb{R}^{m}$. The probability of $f(x, y)$ not exceeding some fixed threshold level $\alpha$ is

$$
\Psi(x, \alpha)=\int_{f(x, y) \leq \alpha} p(y) \mathrm{d} y .
$$

The $\beta$-VaR is defined by the following equation

$$
\operatorname{VaR}_{\beta}(x)=\alpha_{\beta}(x)=\min \{\alpha \mid \Psi(x, \alpha) \geq \beta\},
$$

which means that with probability $\beta$ the losses will not exceed the threshold level $\alpha_{\beta}(x)$ for a given investment strategy $x$.

The $\beta$-CVaR is finally defined by

$$
\operatorname{CVaR}_{\beta}(x)=\phi_{\beta}(x)=(1-\beta)^{-1} \int_{f(x, y) \geq \alpha_{\beta}(x)} f(x, y) p(y) \mathrm{d} y,
$$

which is the expected loss given that the loss exceeds the VaR level, hence conditional expected loss, or Conditional Value-at-Risk. (Note that when clear from the context we will drop $\beta$ and/or $x$ ).

An important parameter of a risk estimation procedure is the confidence level $\beta$, which describes the probability of the event, when our losses exceed a specific (known) level. The risk measure depends on this confidence level $\beta$, so to each $\beta$ corresponds some particular CVaR risk measure, that is we can more precisely talk about $\beta$-CVaR.

\subsection{Portfolio Optimization: Minimizing Risk}

We assume that we have $n$ different technology chains (i.e. coal plus CCS as the first "chain", biomass plus CCS as the second one and wind as a single technology) at our disposal to invest. Values $y^{i}, i=1, \ldots, n$ reflect the return of investment (ROI) for each technology chain. We assume the vector $y=\left[y^{1}, \ldots, y^{n}\right]^{T} \in \mathbb{R}^{n}$ of ROIs to be a random vector having some distribution. We describe the investment strategy using the vector $x=\left[x^{1}, \ldots, x^{n}\right]^{T} \in$ $\mathbb{R}^{n}$ where the scalar value $x^{i}, i=1, \ldots, n$ reflects the portion of capital invested into the 
technology chain number $i$. The return function depends on the chosen investment strategy and the actual ROIs and has the form

$$
g(x, y)=x^{T} y
$$

Because the actual value of ROI is unknown, there is some risk associated with each investment strategy $x$. In order to measure such risk and choose the "best" investment strategy according to it, our portfolio optimization problem will be based on minimizing Conditional Value-atRisk, where the loss function $f(x, y)$ is negative returns

$$
f(x, y)=-x^{T} y .
$$

Note that this is equivalent to maximizing the expected left tail return (-CVaR).

According to Rockafellar and Uryasev (2000) and Palmquist et al (2002), the problem of minimizing CVaR is equivalent to solving a piece-wise linear programming problem, which may be "reduced" to linear programming (LP) problems using auxiliary variables. For both cases, a sample $\left\{y_{k}\right\}_{k=1}^{q}, y_{k} \in \mathbb{R}^{n}$ of the ROI distribution is used to construct the LP problem.

Under the requirement that the investment strategy should provide some minimum expected return (or limited expected loss), the LP problem is equivalent to finding the investment strategy minimizing risk in terms of CVaR as shown below:

$$
\left.\begin{array}{rl}
\min _{(x, \alpha, u)} & \alpha+\frac{1}{q(1-\beta)} \sum_{k=1}^{q} u_{k} \\
\text { s.t. } & e^{T} x=1, m^{T} x \geq R, \quad x \geq 0, u \geq 0 \\
& y_{k}^{T} x+\alpha+u_{k} \geq 0, \quad k=1, \ldots, q
\end{array}\right\}
$$

where $u=\left[u^{1}, \ldots, u^{q}\right]^{T}, u^{k} \in \mathbb{R}, k=1, \ldots, q$ are auxiliary variables, $e \in \mathbb{R}^{n}$ is the vector of ones, $q$ is the sample size, $m \in \mathbb{R}^{n}$ is the expectation of the ROI vector $y$, i.e. $m=\mathbb{E}(y)$, $R$ is the minimum expected portfolio return, $\alpha$ is a threshold of the loss function and $\beta$ is a confidence level. ${ }^{22}$ The part $\left(x_{*}, \alpha_{*}\right)$ of the solution of the LP problem (3.1) gives us the optimal investment strategy $x_{*}$, such that the corresponding $\beta$-CVaR reaches its minimum. $\alpha_{*}$ is the corresponding threshold of the loss function.

Problem (3.1) can be efficiently solved with the help of GAMS ${ }^{23}$ using the BDMLP and CONOPT solvers. The total number of equations and constraints in problem (3.1) and (3.2) is $2 q+n+2$. The execution time of the program solving the aforementioned LP problem for a sample size of $q=10^{4}$ on a Pentium D $3.4 \mathrm{GHz}$ computer running Windows XP Professional Version 2002 Service Pack 2, using GAMS version 2.0.30.1 is less than two minutes. It should be noted that the computational complexity of the problem is mainly defined by the complexity of the underlying mathematical model which produces the sample to be fed into the LP problem solving module - in our case the real options model.

\subsection{Portfolio Optimization: Maximizing Returns}

Under the requirement that the investment strategy should provide maximum expected returns subject to a maximum allowed level of risk (where the constraint is in terms of $\beta$-CVaR),

\footnotetext{
${ }^{22}$ The inequality $-x^{T} y \leq \alpha$ holds with probability greater than $\beta$, that is: $\mathbb{P}\left\{y \mid-x^{T} y \leq \alpha\right\} \geq \beta$.

${ }^{23}$ http://www.gams.com/
} 
the LP problem equivalent to finding the investment strategy is as follows:

$$
\left.\begin{array}{rll}
\min _{(x, \alpha, u)} & -m^{T} x \\
\text { s.t. } & e^{T} x=1, x \geq 0, u \geq 0, \\
& \alpha+\frac{1}{q(1-\beta)} \sum_{k=1}^{q} u_{k} \leq \omega, \\
& y_{k}^{T} x+\alpha+u_{k} & \geq 0, \quad k=1, \ldots, q .
\end{array}\right\}
$$

All the variables have the same meaning as in problem (3.1). The added variable $\omega$ defines the maximum allowed risk in terms of $\beta$-CVaR.

\subsection{Results of the CVaR Approach}

The integrated real options and CVaR approach delivers results, which are in line with our expectations. Table 6 displays the results for the three different scenarios and for different values of $\beta$, ranging from $90 \%$ to $99 \%$, without a return constraint. $R_{e}$ is the expected portfolio return, $\alpha_{*}$ is the upper approximation of VaR (remember that VaR is defined as $\operatorname{VaR}_{\beta}(x)=\alpha_{\beta}(x)=\min \{\alpha\}$ in section 3.1), which is the solution of the problem (3.1). In scenario 2 the solution to the above problem is that all investment goes to wind. However, we have decided to introduce an "artificial" maximum capacity constraint of $10 \%$ on wind for the second scenario, partially because $100 \%$ wind portfolios are usually not feasible in reality due to space restrictions, but mainly because our ultimate goal is to also explore how the other technologies will perform. ${ }^{24}$ In other scenarios there is no need for such an artificial constraint, so we do not apply them in scenarios where the share of wind is less than $100 \%$ without bound. Note that for presentation purposes we have chosen to report - CVaR and -VaR, that is, we go back from (artificially made-up) losses to returns. -VaR of portfolio $x$ at the significance level $\beta$ is thus the $(1-\beta)$-quantile of the portfolio return, and $-\mathrm{CVaR}$ of portfolio $x$ is the conditional expectation of portfolio returns given they are smaller than $-\operatorname{VaR}(x)$. Note that $-\operatorname{CVaR}(x) \leq-\operatorname{VaR}(x)$ and that risk is increasing when $-\mathrm{CVaR}$ is decreasing.

Let us first focus on the results for a fixed $\beta$, e.g. 95\%: For low $\mathrm{CO}_{2}$ prices, we observe that most of the portfolio is composed of coal (90.3\%), the rest is wind. As we go to medium $\mathrm{CO}_{2}$ prices, investors reduce the share of coal and take on some biomass (10.3\%). ${ }^{25}$ In the scenario with high $\mathrm{CO}_{2}$ prices, coal is taken out completely and $88.9 \%$ is invested into biomass and $11.1 \%$ into wind. Biomass becomes more attractive both in terms of its expected return and in terms of $\mathrm{CVaR}$, the higher the $\mathrm{CO}_{2}$ price gets. The optimization would yield different results, in particular for the scenario with high $\mathrm{CO}_{2}$ prices, if the risk measure considered was the variance rather than CVaR (see Section 3.5). Table 6 shows also how the optimal portfolio allocation, expected portfolio return $R_{e}$ and risk in terms of CVaR depend on the confidence level $\beta$. What we see for all scenarios is that expected return decreases and risk increases, as the confidence level grows. So, as we increase the confidence level $\beta$, a larger part of the right tail of the distribution (namely 100 $\beta \%$ ) is captured and the conditional expected return from the smaller left tail $(100(1-\beta) \%)$ is maximized.

By definition, the risk in terms of CVaR for single asset portfolios (only coal, only biomass or only wind) increases with increasing confidence level $\beta$. So it seems plausible that also the

\footnotetext{
${ }^{24}$ We do not know if this $10 \%$ constraint is too small or too big as compared to reality. If we think about the portfolio representing a country like Denmark, then such a constraint could be up to $50 \%$ wind.

${ }^{25}$ If there was no constraint on wind, all investment would go to wind in this case.
} 


\begin{tabular}{l||r|r|r|r} 
& $\beta=90 \%$ & $\beta=95 \%$ & $\beta=97 \%$ & $\beta=99 \%$ \\
\hline \hline Scenario 1 & & & & \\
Coal & 0.0 & 0.0 & 0.0 & 0.0 \\
Biomass & 100.0 & 88.9 & 85.0 & 71.8 \\
Wind & 0.0 & 11.1 & 15.0 & 28.2 \\
\hline$R_{e}$ & 1.861 & 1.856 & 1.854 & 1.848 \\
- VaR $_{\beta}$ & 1.765 & 1.742 & 1.727 & 1.702 \\
$-\mathrm{CVaR}_{\beta}$ & 1.736 & 1.718 & 1.706 & 1.683 \\
\hline \hline Scenario 2 & & & & \\
Coal & 74.3 & 79.7 & 83.0 & 87.5 \\
Biomass & 15.7 & 10.3 & 7.0 & 2.5 \\
Wind & 10.0 & 10.0 & 10.0 & 10.0 \\
\hline$R_{e}$ & 1.712 & 1.710 & 1.708 & 1.706 \\
- VaR $_{\beta}$ & 1.680 & 1.671 & 1.666 & 1.655 \\
- CVaR $_{\beta}$ & 1.669 & 1.662 & 1.657 & 1.648 \\
\hline \hline Scenario 3 & & & & \\
Coal & 88.0 & 90.3 & 90.5 & 92.7 \\
Biomass $_{\text {Wind }}$ & 0.0 & 0.0 & 0.0 & 0.0 \\
\hline$R_{e}$ & 12.0 & 9.7 & 9.5 & 7.3 \\
- VaR $_{\beta}$ & 1.792 & 1.791 & 1.791 & 1.790 \\
- CVaR $_{\beta}$ & 1.753 & 1.755 & 1.750 & 1.739 \\
\hline
\end{tabular}

Table 6: Optimal Portfolio Shares (in \%) for Coal, Biomass and Wind, Expected Returns $R_{e}$, and Risks (CVaR and VaR) for Increasing Confidence Level $\beta$ and a 10\% Capacity Constraint on Wind in Scenario 2 (Scenario 1: high $\mathrm{CO}_{2}$ prices; scenario 2: medium $\mathrm{CO}_{2}$ prices; scenario 3: low $\mathrm{CO}_{2}$ prices. There is no constraint on the minimum level of expected return.)

optimal portfolio risk increases with growing $\beta$, which is exactly what we see in our results. Note that scenario 1 shows a growing share of wind for an increasing confidence level $\beta$. This is probably due to the fact that, for growing values of $\beta$, risk for wind is increasing less substantially than that for biomass. ${ }^{26}$

Intuitively, increasing the confidence level and thus decreasing the incidence of risk, the risk in terms of expected losses in the unfavorable case (CVaR) increases. The latter is quite natural, since the confidence level $\beta$ and CVaR may be deemed as two different aspects of risk: $\beta$ is dealing with the most probable return threshold, and CVaR deals with the return expectation in the unfavorable case. Obviously, one cannot reduce both the $\beta$ and the CVaR simultaneously, but a reasonable balance between those two aspects needs to be found.

Another factor that influences the optimal asset allocation is the specified level of the least expected return, $R$. In Table 7 , we compare the optimization results across scenarios for increasing $R$, where the return constraints are chosen in the following way: The higher $R$ is the value close to the maximum feasible value; the lower $R$ is the minimum expected return among the technologies for a given scenario; and the medium $R$ is an arbitrarily picked

\footnotetext{
${ }^{26}$ In fact, the difference between $-\mathrm{CVaR}_{\beta}$ of biomass and wind is $0.0147,0.0122,0.0110,0.0085$ for $\beta$ equal to $0.9,0.95,0.97,0.99$; so wind gets closer to the lowest-risk biomass with increasing confidence level.
} 
value in between the higher and the lower $R$. In the scenario 1, we observe that the share of biomass increases slightly with rising $R$. Furthermore, Table 7 shows clearly that the values of CVaR do not change substantially for $R=1.858$ and $R=1.861$ in scenario 1 . This means that for high $\mathrm{CO}_{2}$ prices the portfolio risk is quite insensitive to increases in $R$. This is due to the fact that biomass and wind display rather similar degrees of risk, while the expected return of biomass is higher than that of wind (see Table 3); hence the shift towards biomass with increasing required returns. ${ }^{27}$

\begin{tabular}{l||r|r|r}
\hline Scenario 1 & $R=1.658$ & $R=1.858$ & $R=1.861$ \\
\hline Coal & 0.0 & 0.0 & 0.0 \\
Biomass & 88.9 & 93.4 & 99.8 \\
Wind & 11.1 & 6.6 & 0.2 \\
\hline$R_{e}$ & 1.856 & 1.858 & 1.861 \\
- VaR $_{0.95}$ & 1.742 & 1.743 & 1.743 \\
CVaR $_{0.95}$ & 1.718 & 1.717 & 1.717 \\
\hline \hline Scenario 2 & $R=1.692$ & $R=1.720$ & $R=1.748$ \\
\hline Coal & 79.7 & 57.9 & 0.2 \\
Biomass & 10.3 & 32.1 & 89.8 \\
Wind & 10.0 & 10.0 & 10.0 \\
\hline$R_{e}$ & 1.710 & 1.720 & 1.748 \\
- VaR & 1.971 & 1.671 & 1.660 \\
- CVaR $_{0.95}$ & 1.662 & 1.659 & 1.641 \\
\hline \hline Scenario 3 & $R=1.668$ & $R=1.80$ & $R=1.81$ \\
\hline Coal & 90.3 & 55.7 & 17.6 \\
Biomass $_{\text {Wind }}$ & 0.0 & 0.0 & 0.0 \\
\hline$R_{e}$ & 9.7 & 44.3 & 82.4 \\
- VaR $_{0.95}$ & 1.791 & 1.80 & 1.81 \\
- CVaR $_{0.95}$ & 1.755 & 1.749 & 1.734 \\
\hline
\end{tabular}

Table 7: Optimal Portfolio Shares (in \%), Expected Returns $R_{e}$ and Risks (CVaR and VaR) for Increasing Levels of Minimum Expected Return $R$ and a $10 \%$ Capacity Constraint on Wind in Scenario 2

In scenario 2 there is a clear shift from a coal-dominated to a biomass-dominated portfolio with an increasing minimal required return $R$. Note, however, the upper bound on wind allocations - otherwise the optimal portfolio would be completely wind-dominated. The shift from coal to biomass is due to the specific risk levels and expected returns shown by the two respective technologies (see Table 3 ). The coal-fired power plant displays only a slightly lower degree of risk but a clearly lower expected return than biomass. The portfolio re-balancing with increasing $R$, as stated above, can be easily understood then: while with a comparatively low $R$ the major portfolio allocation is in the lowest-risk technology feasible, which is coal (wind is constrained), the allocation shifts toward biomass, which displays only slightly higher

\footnotetext{
${ }^{27}$ Note that taking the variance as a risk measure would yield completely different optimization results, which is due to the different risk levels in terms of $\mathrm{CVaR}$ and variance displayed by the different technologies (see Section 3.5).
} 
risk but clearly larger return, with increasing $R$.

In scenario 3 (without the bound on wind) the optimal portfolio is re-balanced from being coal-dominated to being wind-dominated, which can again be explained by the risk and expected return numbers of the three underlying technologies. First, biomass is not interesting, since it displays the highest risk and lowest expected return. Coal shows a lower risk than wind, but also a lower return. So it is not surprising that with increasing required returns $R$ the optimal portfolio allocation shifts from the less risky coal to the slightly more risky but also more profitable wind technology.

\begin{tabular}{l||r|r|r}
\hline Scenario 1 & $-\phi=1.7174$ & $-\phi=1.71745$ & $-\phi=1.7175$ \\
\hline Coal & 0.0 & 0.0 & 0.0 \\
Biomass & 97.9 & 94.9 & 90.0 \\
Wind & 2.1 & 5.1 & 10.0 \\
\hline$R_{e}$ & 1.860 & 1.859 & 1.856 \\
- VaR & 1.743 & 1.743 & 1.742 \\
\hline \hline Scenario 2 & $-\phi=1.645$ & $-\phi=1.650$ & $-\phi=1.660$ \\
\hline Coal & 11.9 & 26.7 & 64.5 \\
Biomass & 78.1 & 63.3 & 25.5 \\
Wind & 10.0 & 10.0 & 10.0 \\
\hline$R_{e}$ & 1.743 & 1.735 & 1.717 \\
- VaR & 1.663 & 1.666 & 1.671 \\
\hline \hline Scenario 3 & $-\phi=1.716$ & $-\phi=1.736$ & $-\phi=1.745$ \\
\hline Coal & 17.9 & 54.9 & 80.8 \\
Biomass & 0.0 & 0.0 & 0.0 \\
Wind & 82.1 & 45.1 & 19.2 \\
\hline$R_{e}$ & 1.810 & 1.800 & 1.793 \\
-VaR & 1.735 & 1.749 & 1.755 \\
\hline
\end{tabular}

Table 8: Portfolio Shares (in \%), Expected Returns $R_{e}$, and Risk VaR for Decreasing Levels of Risk in Terms of Maximum-CVaR, $-\phi$, and Confidence Level $\beta=95 \%$ (All the CVaR constraints are active, i.e. the actual value of $-\mathrm{CVaR}$ is equal to the constraint value $-\phi$.)

In general, the degree and direction of portfolio re-balancing with increasing minimal returns depend on the risk and return structure of the underlying assets. In particular, it depends on the difference between risk and expected return levels of the assets. In our situation, biomass has the highest expected return and, at the same time, the lowest degree of risk in scenario 1 ; the same is true for wind in scenario 2 . This explains why a major part of the optimal portfolio in the first scenario is invested into biomass; in the scenario 2, the situation is different due to the upper bound on wind allocations. In the third scenario, coal displays the lowest risk, while the highest expected return is gained by investing in wind, which explains the portfolio re-balancing from a coal-dominated allocation to a portfolio, where wind is prevalent. In addition, coal displays the highest risk and lowest expected return in the first scenario and hence is clearly dominated by the other two technologies. The same applies to biomass in the third scenario. This is why optimal portfolios do never include coal in the first scenario and biomass in the third scenario.

Table 8 shows the investment strategies and corresponding expected returns under a CVaR 
risk constraint. Scenario 1 is quite insensitive to and therefore stable across different CVaR restrictions, so both expected return and risk $\alpha_{*}$ change only slightly, when the CVaR restriction changes. In other scenarios, this insensitivity only holds up to a certain level, beyond which the portfolios change substantially: While there is no outstanding technology change in the portfolio composition in scenario 1 , in scenarios 2 and 3 coal replaces biomass and wind respectively, as the maximum allowed risk decreases. Furthermore, Table 8 shows a slight increase in risk $\alpha_{*}$ for the lower admissible level of CVaR-risk $\phi$ for scenario 1. Please note that this is not contradictory, since section 3.2 explained that $\alpha_{*}$ is the threshold of the loss function, which is the upper approximation of $\beta$-VaR and not necessarily the exact value of $\beta$-VaR according to its definition in section 3.1.

\subsection{Mean-variance versus CVaR}

In spite of its failures in the case of non-normal or non-symmetric distributions the meanvariance (M-V) approach posed by Markowitz, see Markowitz (1959), still enjoys widespread acceptance as a practical tool for portfolio construction, and many investment firms routinely compute mean-variance efficient portfolios. Rockafellar and Uryasev (2000) have shown that under certain conditions the $\mathrm{CVaR}$ approach and the $\mathrm{M}-\mathrm{V}$ approach are equivalent in terms of providing the same optimal asset allocations. Thus, the CVaR approach can be viewed in some sense as a generalization of the $\mathrm{M}-\mathrm{V}$ approach when dealing with non-normal or nonsymmetric distributions. From this perspective it makes sense to consider the M-V approach as a benchmark case and thus to compare its performance to that of CVaR.

The M-V optimization problem under consideration is formulated as follows

$$
\min \left\{x^{T} C x \mid x \geq 0, m^{T} x \geq R, e^{T} x=1\right\}
$$

where $C$ is the covariance matrix of the return distribution of instruments under consideration, $x \in \mathbb{R}^{n}$ is the vector of portfolio holdings, $m \in \mathbb{R}^{n}$ is the vector of expected returns, $e \in \mathbb{R}^{n}$ is the vector of ones and parameter $R \in \mathbb{R}$ is the minimum expected return. Under the joint normality assumption of returns, the portfolio distribution, which is normal, is uniquely defined by its first two moments (mean and variance). In the $\mathrm{M}-\mathrm{V}$ framework, risk is defined as the variance of the portfolio return, $x^{T} C x$, and thus the task is to minimize portfolio variance with respect to a certain aversion towards risk, which is represented by the minimum expected return $R$ the portfolio needs to achieve. Note that for a small number of instruments (in our case $n=3$ ), the quadratic programming (QP) problem (3.3) will be solved much faster than the linear programming problem for solving CVaR. ${ }^{28}$

Table 9 and Figure 5 present comparisons of different performance measures computed for the $\mathrm{M}-\mathrm{V}$ and $\mathrm{CVaR}$ portfolios for different minimum values of expected returns, $R$, as reported in Table 7. As an additional reference case we have calculated M-V portfolios under the assumption of uncorrelated returns of our power plants. ${ }^{29}$

As performance measures we use expected return, variance, $-\mathrm{CVaR}$ and -VaR. Preferred outputs are larger values of expected returns, $-\mathrm{CVaR},-\mathrm{VaR}$; and smaller values of variances.

\footnotetext{
${ }^{28}$ The LP problem for finding the portfolio with minimum CVaR has $q+n+1=10,004$ variables while the QP problem for finding the M-V portfolio has only $n=3$ variables.

${ }^{29}$ There is a closed form solution for solving the parametric quadratic programming problems under the assumption that the covariance matrix is diagonal, and for a certain range of parameter $R$ the portfolio will be diversified by construction (see Best and Hlouskova, 2000).
} 
In scenario 1 (high $\mathrm{CO}_{2}$ prices), CVaR portfolios show a performance which is clearly superior to that of M-V portfolios for $R \in\{1.658,1.75\}$, see the density plots of both portfolios at the first line in Figure 5 where the majority of the mass of CVaR portfolios is to the right of the mass of M-V portfolios. For both values of $R$ under consideration $(R=1.658$, which is the return of the coal-fired power plant, and $R=1.75$ ), CVaR portfolios outperform M-V portfolios when the portfolio performance is measured by expected return, CVaR and VaR. The return of the M-V portfolio has smaller variance than the one of the CVaR portfolio. Interestingly, the M-V portfolio with assumed uncorrelated power plants' returns shows a better performance with respect to all measures (but variance) than the $\mathrm{M}-\mathrm{V}$ portfolio with the true covariance matrix. Portfolio holdings between $\mathrm{CVaR}$ and $\mathrm{M}-\mathrm{V}$ portfolios differ quite dramatically: while the CVaR approach poses most weight to the biomass-fired power plant, the $\mathrm{M}-\mathrm{V}$ approach places most weight to the coal-fired power plant (when $R=1.658$ ) and to the coal-fired power plant and the wind mill (when $R=1.75$ ). For $R \in\{1.858,1.861\}$ the $\mathrm{M}-\mathrm{V}$ and $\mathrm{CVaR}$ portfolios coincide.

The differences in the portfolio performance between $\mathrm{M}-\mathrm{V}$ and $\mathrm{CVaR}$ are significantly smaller in scenario 2 (medium $\mathrm{CO}_{2}$ prices). The deterioration of the performance of the CVaR portfolio compared to the unconstrained $\mathrm{M}-\mathrm{V}$ portfolio for bigger $R$ comes from the imposition of $10 \%$ upper bound on wind-mill holdings (otherwise CVaR portfolio consists only of the wind-mill). For $R=1.692$ the CVaR portfolio still performs best (except for the variance). However, when comparing it with the $\mathrm{M}-\mathrm{V}$ portfolio with zero correlations then all the performance measures as well as portfolio holdings are in the same ballpark. For higher values of the expected return, $R \in\{1.72,1.748\}$, the $\mathrm{M}-\mathrm{V}$ portfolio where the $10 \%$ bound on wind-mill holdings was not imposed outperforms the constrained CVaR portfolio in all measures but expected return which is the same. Note that when the $10 \%$ bound on wind-mill holdings was imposed also in the $\mathrm{M}-\mathrm{V}$ problem, then the $\mathrm{CVaR}$ and $\mathrm{M}-\mathrm{V}$ portfolios coincide.

The CVaR portfolio seems to perform best in scenario 3 (low $\mathrm{CO}_{2}$ prices) only in the case when $R=1.688$ for all measures but variance. For $R=1.791$, which is far from its maximum value (see Table 6 on expected returns of power plants), the CVaR and M-V portfolios are more or less the same (the density plots are nearly identical). The next empirical observation follows also from Proposition 1 in Rockafellar and Uryasev (2000), which says that under certain assumptions CVaR and $\mathrm{M}-\mathrm{V}$ portfolios coincide. These assumptions are: the return associated with each portfolio is normally distributed, $\beta \geq 0.5$ and the constraint on expected return is active. We have performed a normality test on the $\mathrm{M}-\mathrm{V}$ and $\mathrm{CVaR}$ portfolios for $R=1.791$ in scenario 3 , and the null hypothesis on normality was not rejected at the $10 \%$ significance level. ${ }^{30}$ Note that expected returns of both portfolios coincide with $R=1.791$; i.e. the return constraint is active. Thus, observing identical density plots does not come as a surprise. On the other hand, $\mathrm{M}-\mathrm{V}$ and $\mathrm{CVaR}$ portfolios coincide for $R \in\{1.8,1.81\}$, their constraints on expected returns are active, and their return distribution is non-normal. ${ }^{31}$

Thus, the main observation is that the performance differences between $\mathrm{CVaR}$ and $\mathrm{M}-\mathrm{V}$ portfolios are largest for scenario 1 (high $\mathrm{CO}_{2}$ prices). One cannot see such pronounced differences in performance measures in scenarios 2 and 3 , where $\mathrm{CO}_{2}$ prices are equal to the

\footnotetext{
${ }^{30}$ This could be the consequence of the fact that normality was not rejected at the $10 \%$ significance level for the return distribution of the coal-fired power plant, and the biggest weight (app. 90\%) was allocated to this power plant.

${ }^{31}$ In these cases most of the weight is allocated to the biomass-fired power plant where the null hypothesis of the return distribution being normal was rejected at the $1 \%$ significance level.
} 
mean and low respectively. The same concerns portfolio holdings. This observation opposes the observation made in Krokhmal, Palmquist and Uryasev (2001), where no significant differences between CVaR and M-V portfolios were noticed. However, as the authors mention, their result is dataset-specific - and so is ours. The significant differences between the performance of $\mathrm{CVaR}$ and $\mathrm{VaR}$ portfolios and the massive outperformance of CVaR portfolios in scenario 1 have to be associated with the fact that individual plant returns and portfolio returns are non-normal. A normality test for the M-V portfolio returns showed that the null hypothesis of normality can be rejected. ${ }^{32}$ We find our exercise a helpful demonstration of advantages of the CVaR approach over the M-V approach. We have also empirically confirmed that the M-V approach is embedded in the CVaR framework (by simple application of the findings of Rockafellar and Uryasev (2000)). Thus, being cautious when choosing the portfolio optimization approach seems to be a wise idea.
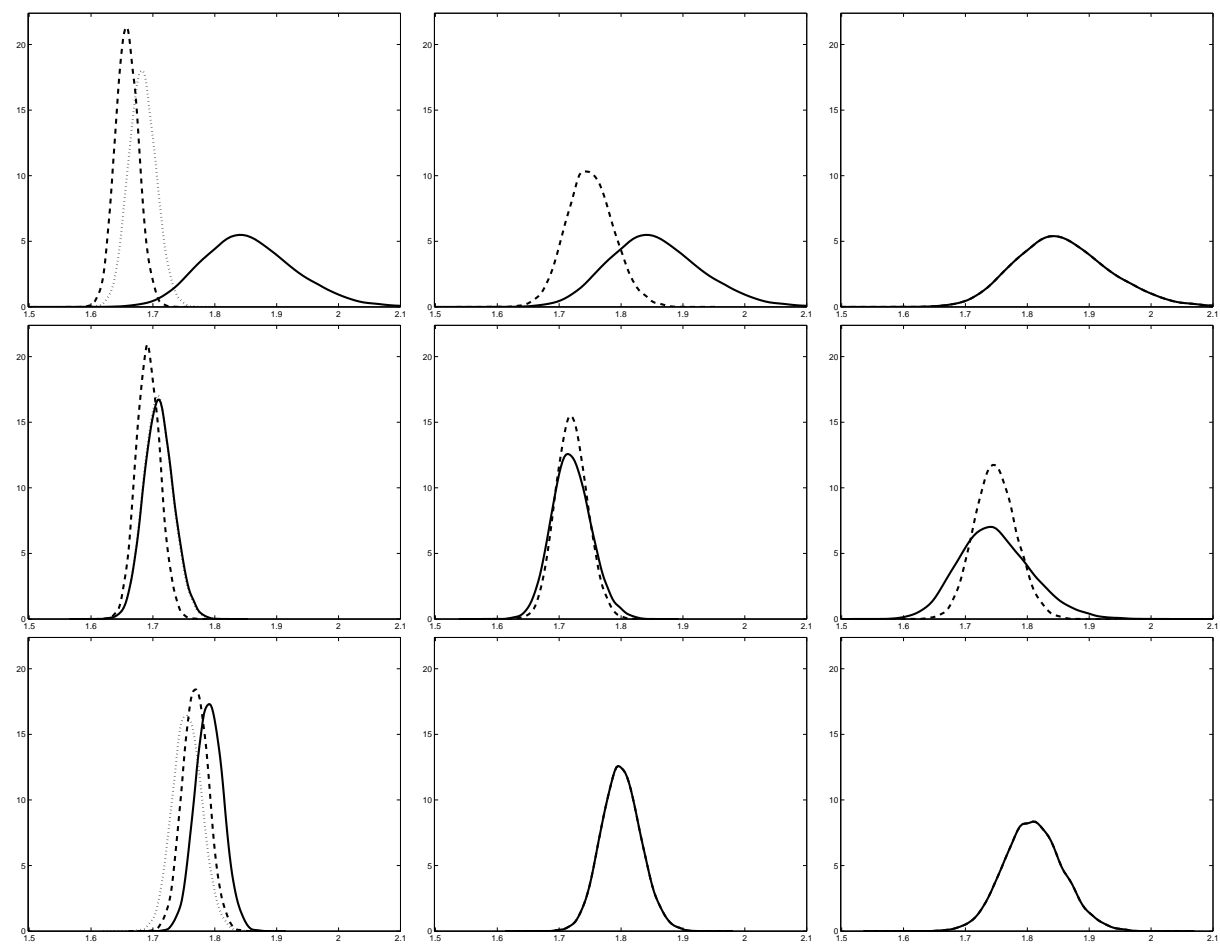

Figure 5: Density Plots of Returns of $C V a R$ and $M-V$ Portfolios (Row 1: Scenario 1 (high $\mathrm{CO}_{2}$ prices). Row 2: Scenario 2 (medium $\mathrm{CO}_{2}$ prices). Row 3: Scenario 3 (low $\mathrm{CO}_{2}$ prices). The black solid line corresponds to $\mathrm{CVaR}$, the dashed line to $\mathrm{M}-\mathrm{V}$ and the dotted line to $\mathrm{M}-\mathrm{V}$ portfolios (no correlation assumption). Figure 1 in the row 1 has $R=1.658$, Figure 2 has $R=1.75$, and Figure 3 has $R=1.858$. In row $2 R$ is chosen as follows (left to right): $R=1.692,1.7202,1.7484$. The upper bound is imposed in scenario 2 for the CVaR model: $x_{3} \leq 0.1$ ( $x_{3}$ corresponds to holdings of wind). In row $3 R$ is chosen as follows (left to right): $R=1.668,1.8,1.81 . \beta=95 \%$ for CVaR portfolios).

\footnotetext{
${ }^{32}$ All normality tests were conducted by applying the Jarque-Bera test.
} 


\begin{tabular}{c|c|c|c||r|r|r||c|c|c|c}
\hline Scenario & $\mathrm{R}$ & Additional constraint & Opt. type & Coal & Biomass & Wind & $\mathrm{R}_{e}$ & Variance (\%) & -CVaR & -VaR \\
\hline \hline 1 & 1.658 & - & $\mathrm{M}-\mathrm{V}$ & 100.0 & 0.0 & 0.0 & 1.658 & 0.034 & 1.621 & 1.628 \\
1 & 1.658 & uncorrelated returns & $\mathrm{M}-\mathrm{V}$ & 85.5 & 4.8 & 9.7 & 1.683 & 0.049 & 1.639 & 1.648 \\
1 & 1.658 & - & $\mathrm{CVaR}$ & 0.0 & 88.9 & 11.1 & 1.856 & 0.560 & 1.718 & 1.742 \\
\hline 1 & 1.750 & - & $\mathrm{M}-\mathrm{V}$ & 45.3 & 13.7 & 41.0 & 1.750 & 0.140 & 1.675 & 1.690 \\
1 & 1.750 & - & $\mathrm{CVaR}$ & 0.0 & 88.9 & 11.1 & 1.856 & 0.560 & 1.718 & 1.742 \\
\hline 1 & 1.858 & - & $\mathrm{M}-\mathrm{V}, \mathrm{CVaR}$ & 0.0 & 93.4 & 6.6 & 1.858 & 0.582 & 1.717 & 1.743 \\
\hline 1 & 1.861 & - & $\mathrm{M}-\mathrm{V}, \mathrm{CVaR}$ & 0.0 & 99.8 & 0.2 & 1.861 & 0.614 & 1.717 & 1.743 \\
\hline \hline 2 & 1.692 & - & $\mathrm{M}-\mathrm{V}$ & 100.0 & 0.0 & 0.0 & 1.692 & 0.037 & 1.654 & 1.661 \\
2 & 1.692 & uncorrelated returns & $\mathrm{M}-\mathrm{V}$ & 81.4 & 8.6 & 10.0 & 1.709 & 0.056 & 1.661 & 1.671 \\
2 & 1.692 & $x_{3} \leq 0.1$ & $\mathrm{CVaR}$ & 79.7 & 10.3 & 10.0 & 1.709 & 0.060 & 1.662 & 1.671 \\
\hline 2 & 1.720 & - & $\mathrm{M}-\mathrm{V}$ & 77.2 & 0.0 & 22.8 & 1.720 & 0.070 & 1.668 & 1.679 \\
2 & 1.720 & $x_{3} \leq 0.1$ & $\mathrm{M}-\mathrm{V}, \mathrm{CVaR}$ & 57.9 & 32.1 & 10.0 & 1.720 & 0.100 & 1.659 & 1.671 \\
\hline 2 & 1.748 & - & $\mathrm{M}-\mathrm{V}$ & 54.1 & 0.0 & 45.9 & 1.748 & 0.115 & 1.681 & 1.695 \\
2 & 1.748 & $x_{3} \leq 0.1$ & $\mathrm{M}-\mathrm{V}, \mathrm{CVaR}$ & 0.2 & 89.8 & 10.0 & 1.748 & 0.337 & 1.641 & 1.660 \\
\hline \hline 3 & 1.668 & - & $\mathrm{M}-\mathrm{V}$ & 83.9 & 16.1 & 0.0 & 1.769 & 0.043 & 1.727 & 1.735 \\
3 & 1.668 & uncorrelated returns & $\mathrm{M}-\mathrm{V}$ & 61.6 & 29.1 & 9.3 & 1.756 & 0.055 & 1.708 & 1.718 \\
3 & 1.668 & - & $\mathrm{CVaR}$ & 90.3 & 0.0 & 9.7 & 1.791 & 0.049 & 1.746 & 1.755 \\
\hline 3 & 1.791 & - & $\mathrm{M}-\mathrm{V}$ & 91.2 & 0.0 & 8.8 & 1.791 & 0.049 & 1.746 & 1.755 \\
3 & 1.791 & - & $\mathrm{CVaR}$ & 90.3 & 0.0 & 9.7 & 1.791 & 0.052 & 1.746 & 1.755 \\
\hline 3 & 1.800 & - & $\mathrm{M}-\mathrm{V}, \mathrm{CVaR}$ & 55.7 & 0.0 & 44.3 & 1.800 & 0.073 & 1.736 & 1.749 \\
\hline 3 & 1.810 & - & $\mathrm{M}-\mathrm{V}, \mathrm{CVaR}$ & 17.6 & 0.0 & 82.4 & 1.810 & 0.205 & 1.716 & 1.734 \\
\hline
\end{tabular}

Table 9: Portfolio Allocations (in \%) and Performance for $M$ - $V$ and $C V a R$ Portfolios Scenario 1 represents high $\mathrm{CO}_{2}$ prices, scenario 2 represents medium $\mathrm{CO}_{2}$ prices and scenario 3 represents low $\mathrm{CO}_{2}$ prices. $R_{e}$ is the expected return, $\beta=95 \%$, and $x_{3}$ corresponds to the holdings of the wind farm. 


\section{Conclusion}

Energy investments have raised the interest of many large investors recently. The enactment of climate change policies aiming to reduce $\mathrm{CO}_{2}$ emissions by punishing fossil fuel technologies through taxes and the establishment of permit trading schemes have made investments in the electricity sector different from what they were before: More environmentally friendly technologies, which had previously been largely unprofitable due to high capital and operations \& maintenance cost and low load factors (e.g. wind energy suffers from the fact that wind does not always blow at constant speed), have become much more attractive in the light of these new climate change policies.

It has been shown in several studies (e.g. Fuss et al, 2006; Laurikka and Koljonen, 2006) that the uncertainties originating in the $\mathrm{CO}_{2}$ price and the electricity price, which the individual power plant investor faces, can be incorporated in the investment decision by using real options modeling. However, if we think of larger power plant investors or banks providing funds to those investors, it seems to be natural that they would like to diversify investments. A bank, for example, will provide funds not only to power plants with high expected returns, since these usually come at the cost of higher risk, but also to power plants with lower expected returns, if they can demonstrate on solid grounds that they are exposed to a lower degree of risk.

While these diversification ideas are generally familiar through the work of Nobel laureate Markowitz (1952), they have - so far - not been extensively applied to investment planning in the electricity sector. We have therefore developed a portfolio optimization approach which uses the return distributions resulting from a decision-making process of the power plant producer within a real options framework. As a measure of risk we have chosen CVaR because we think it is more appropriate for our problem than the traditional mean-variance approach for a multitude of advantages listed in previous sections. Under mild assumptions, Value-at-Risk minimization, conditional Value-at-Risk minimization and the mean-variance approach all yield the same results, provided that all underlying distributions are normal. We have seen, however, that the (bivariate) dependence structure between different returns fails to be normal. Results from estimating a restricted symmetric version of a fairly flexible copula showed that in nearly all cases (coal/biomass, coal/wind and biomass/wind in the three scenarios) the null hypothesis of symmetry could be rejected. This seems to be clear evidence of non-normality in the total joint return distribution and thus implies that it is more sensible to use the CVaR approach in portfolio optimization than the mean-variance (M-V) approach where the return distribution is supposed to be normally distributed. Our empirical results in terms of comparisons of different performance measures of the CVaR and the $\mathrm{M}-\mathrm{V}$ portfolios as well as the density plots of return distributions of these portfolios (mainly for the scenario with high $\mathrm{CO}_{2}$ prices) are clear consequences of this evidence.

Our results show that the combined RO-CVaR approach is indeed a valuable contribution to the existing theory on investment under uncertainty in the electricity sector. More specifically, we find that the results are in line with what we would expect in terms of diversification: As we increase the level of $\beta$ the investor starts to favor low-risk over high-risk technologies, even if expected returns are lower. With respect to the minimum expected return $R$ that the investor specifies, the portfolios shift to technologies with higher expected returns as $R$ increases. So, the extent of the risk looses importance in the investment decision if the expected return that the investor wants to secure gets higher.

From a policy perspective, we can say that already for low $\mathrm{CO}_{2}$ prices, the mere fact that 
the investor wants to diversify to reduce the risk for a given return leads to the inclusion of renewables (here wind) into the portfolio because with increasing $\mathrm{CO}_{2}$ prices, wind is relatively more profitable than investors might initially have assumed. Fossil fuel technologies (here coal), on the other hand have more stable returns, so they make up the larger part of the portfolio in the case of low $\mathrm{CO}_{2}$ prices. For coal, expected returns fall, as we go from the third to the first scenario. In the first scenario biomass has an expected return even larger than wind, but the fact that biomass and wind display similar degrees of risk leads to the inclusion of both technologies in the optimal portfolio. Finally, in the first scenario, fossil fuels (coal) do no longer play a major role, which is exactly what policymakers want to achieve by raising the price of $\mathrm{CO}_{2}$ more sharply. 


\section{Appendix A: Snapshots of Price Distributions for All Scenarios}
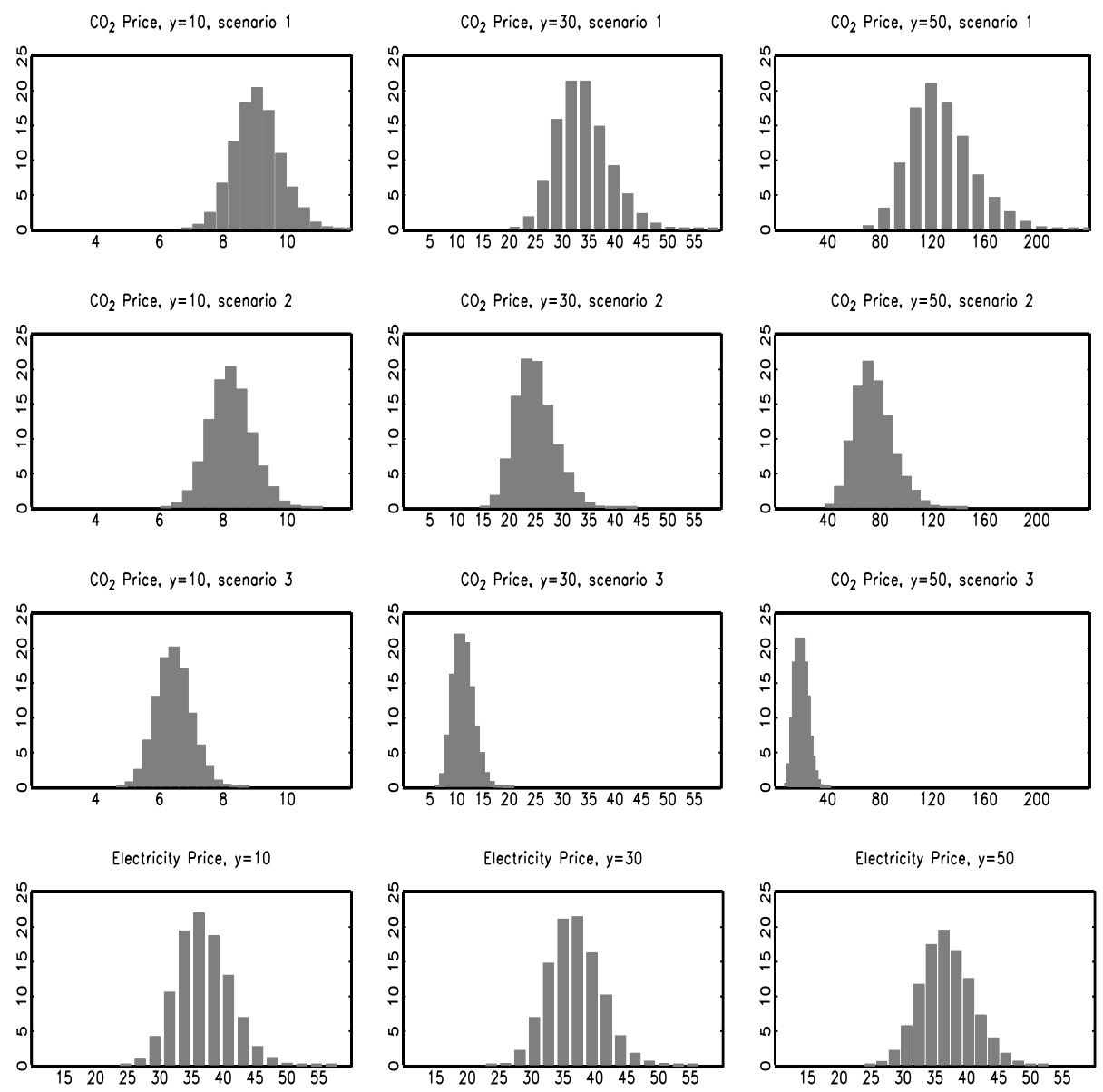

Figure A.1: Price Distributions of $\mathrm{CO}_{2}$ in Scenarios 1, 2, 3 and of Electricity (The graph presents bar charts of $\mathrm{CO}_{2}$ prices for scenarios 1, 2 and 3, and of electricity prices (top to bottom) for years 10, 30 and 50 (left to right). The horizontal axis shows prices in $€$, the vertical axis shows frequencies in \%.) 


\section{Appendix B: Real Options Output for Investing and Switching}
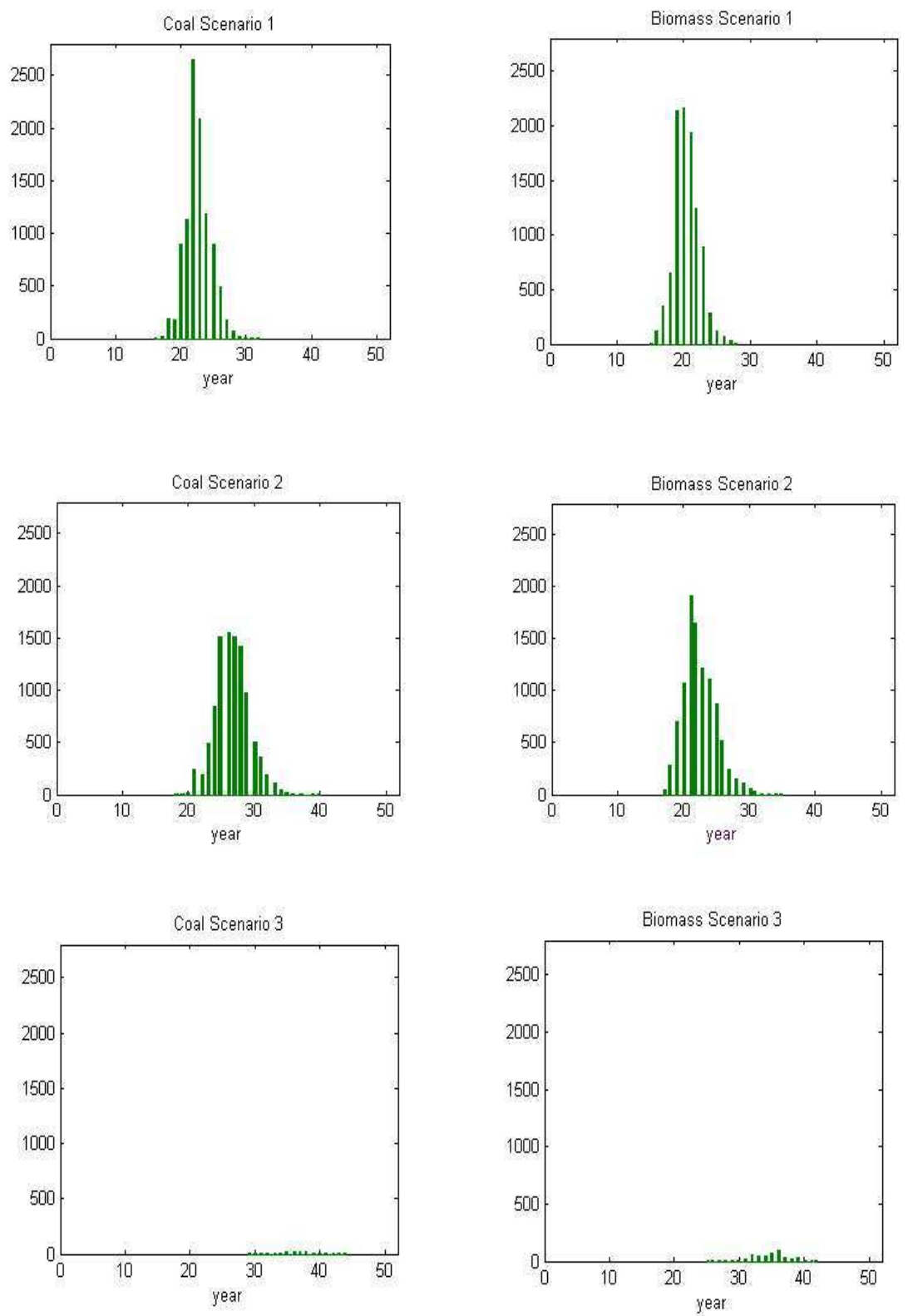

Figure B.1: Investment Frequencies for Adding CCS to Coal (left) and Biomass (right) for Three Scenarios (high $\mathrm{CO}_{2}$ prices (top row), normal $\mathrm{CO}_{2}$ prices (middle row), low $\mathrm{CO}_{2}$ prices (bottom row) for 10,000 simulations) 

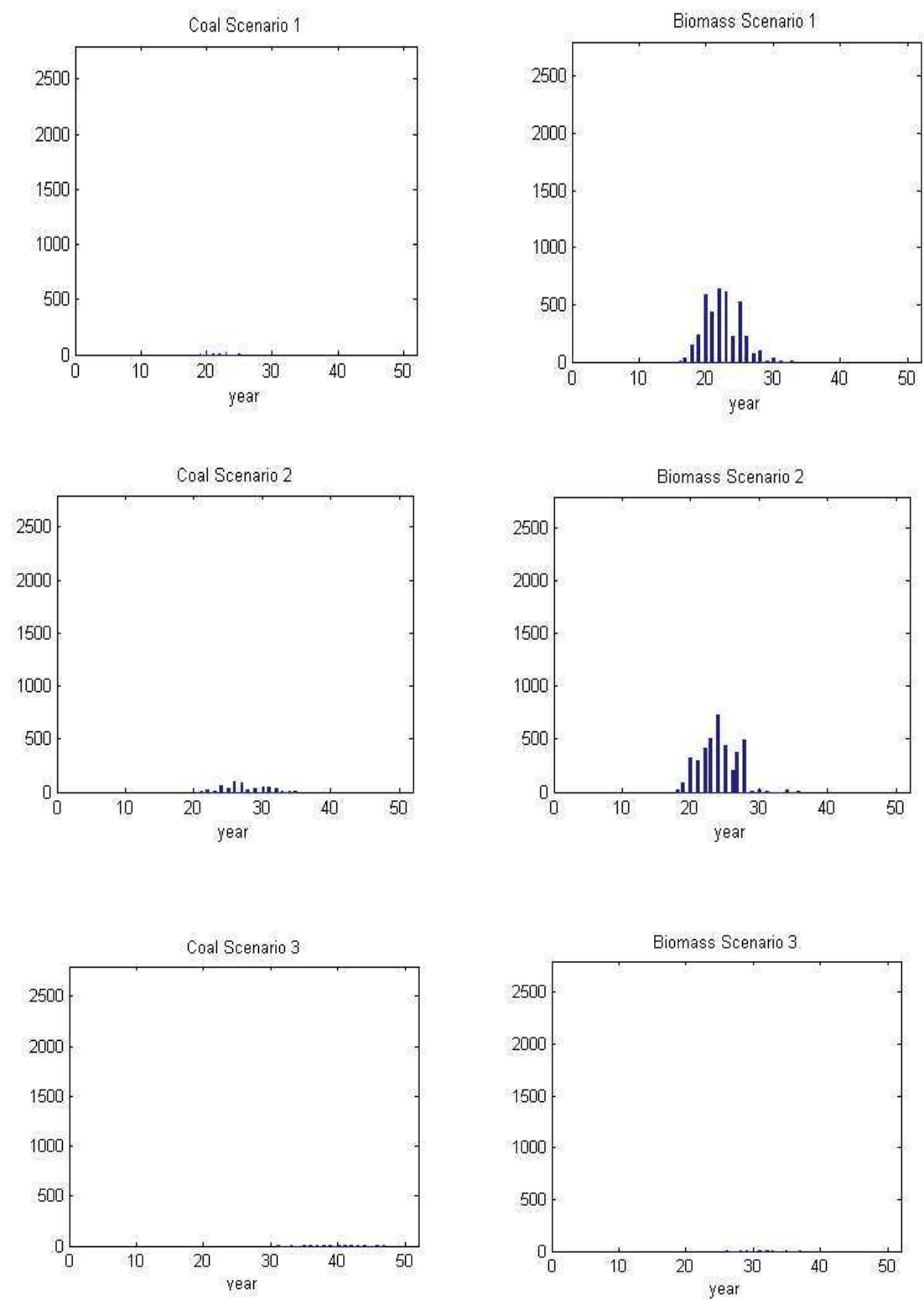

Figure B.2: Frequencies of Switching the CCS Module Off for Coal (left) and Biomass (right)(high $\mathrm{CO}_{2}$ prices (top row), normal $\mathrm{CO}_{2}$ prices (middle row), low $\mathrm{CO}_{2}$ prices (bottom row) for 10,000 simulations) 

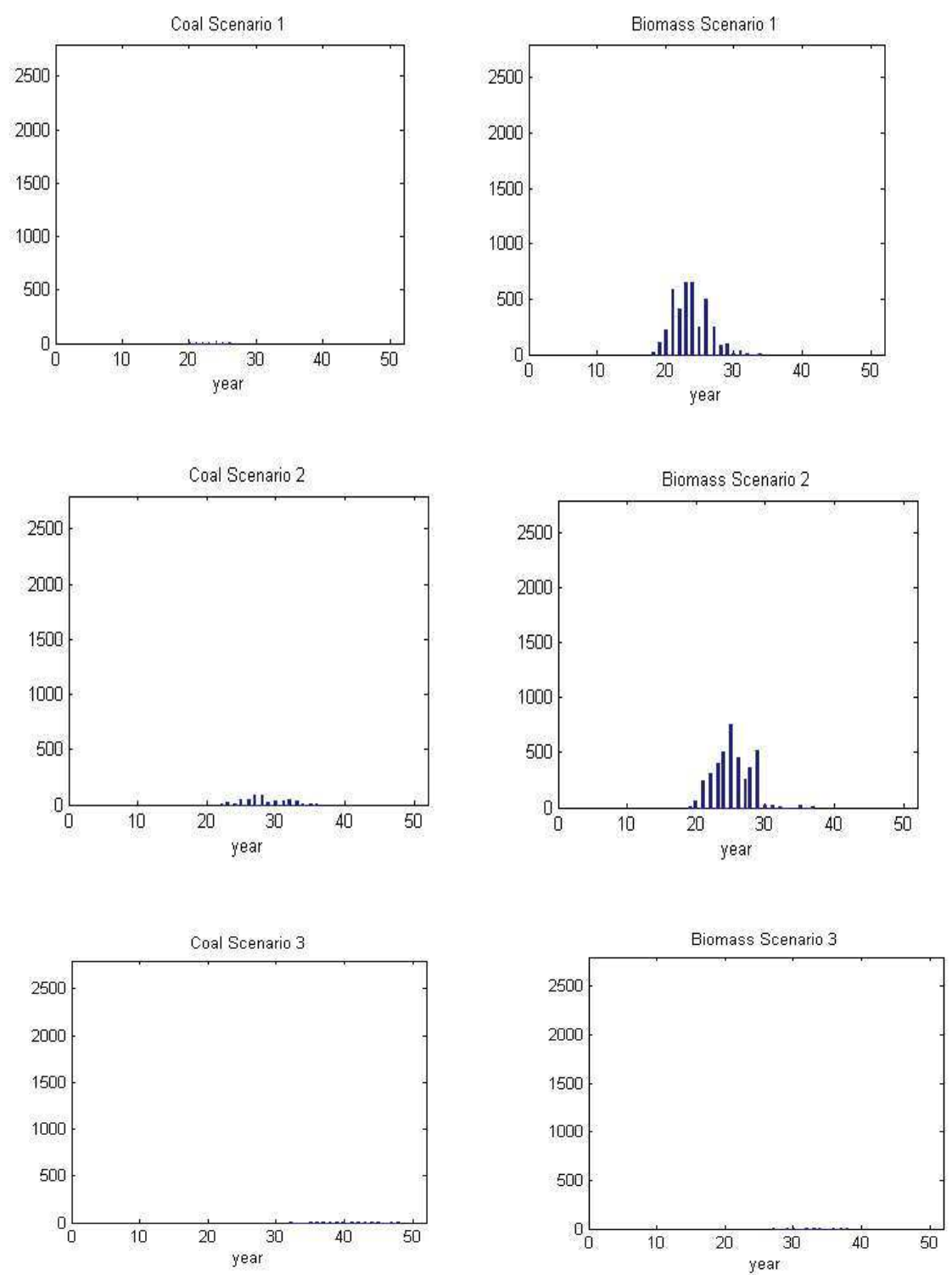

Figure B.3: Frequencies of Switching the CCS Module On for Coal (left) and Biomass (right) (high $\mathrm{CO}_{2}$ prices (top row), normal $\mathrm{CO}_{2}$ prices (middle row), low $\mathrm{CO}_{2}$ prices (bottom row) for 10,000 simulations) 


\section{Appendix C: Definitions of Copulas and Related Concepts}

A copula is a function $C: I^{2}=[0,1]^{2} \rightarrow I$, satisfying, for $0 \leq u \leq 1$ and $u_{1} \leq u_{2}, v_{1} \leq$ $v_{2},\left(u_{1}, u_{2}\right),\left(v_{1}, v_{2}\right) \in I^{2}$, the conditions

$$
\begin{gathered}
C(u, 0)=C(0, u)=0, \quad C(u, 1)=C(1, u)=u, \\
C\left(u_{2}, v_{2}\right)-C\left(u_{1}, v_{2}\right)-C\left(u_{2}, v_{1}\right)+C\left(u_{1}, v_{1}\right) \geq 0 .
\end{gathered}
$$

The second condition means that $P\left(u_{1} \leq U \leq u_{2}, v_{1} \leq V \leq v_{2}\right) \geq 0$ for $(U, V)$ having joint distribution function $C$. See Nelsen (2006) for further details.

To better understand the concept of a copula consider Sklar's theorem. Let $F$ be the distribution function of random variables $(X, Y)$ with marginal distribution functions $F_{1}$ and $F_{2}$. Then there exists a copula $C: I^{2} \rightarrow I$ such that, for all $(X, Y)$,

$$
F(X, Y)=C\left(F_{1}(X), F_{2}(Y)\right) .
$$

If $F_{1}$ and $F_{2}$ are continuous, then $C$ is unique. Otherwise, $C$ is uniquely determined on $\operatorname{Ran} F_{1} \times \operatorname{Ran} F_{2}$. The copula can be computed as $C(U, V)=F\left(F_{1}^{-1}(X), F_{2}^{-1}(Y)\right)$. Conversely, if $C$ is a copula and $F_{1}$ and $F_{2}$ are one-dimensional distribution functions, then the function $F$ defined by (C.3) is a two-dimensional distribution function with margins $F_{1}, F_{2}$. Clearly, a copula itself is a distribution function. Note that random variables transformed by their marginal probability distribution functions, i.e. $F_{1}(X)$ and $F_{2}(Y)$, are standard uniform random variables $(U, V)$.

Let $C$ be a copula. Then lower tail dependence and upper tail dependence are defined as

$$
\begin{aligned}
& \lambda_{L}=\lim _{\alpha \rightarrow 0^{+}} P(U \leq \alpha \mid V \leq \alpha)=\lim _{\alpha \rightarrow 0^{+}} \frac{C(\alpha, \alpha)}{\alpha}, \\
& \lambda_{U}=\lim _{\alpha \rightarrow 0^{+}} P(U>1-\alpha \mid V>1-\alpha)=\lim _{\alpha \rightarrow 0^{+}} \frac{2 \alpha-1+C(1-\alpha, 1-\alpha)}{\alpha},
\end{aligned}
$$

provided the limit exists. Note that $0 \leq \lambda_{L}, \lambda_{U} \leq 1$. Using Sklar's theorem, lower and upper tail dependence can also be understood in terms of random variables $X$ and $Y$ with marginal distribution functions $F_{1}$ and $F_{2}$, viz

$$
\begin{aligned}
& \lambda_{L}=\lim _{\alpha \rightarrow 0+} P\left[X \leq F_{1}^{-1}(\alpha) \mid Y \leq F_{2}^{-1}(\alpha)\right], \\
& \lambda_{U}=\lim _{\alpha \rightarrow 0+} P\left[X>F_{1}^{-1}(1-\alpha) \mid Y>F_{2}^{-1}(1-\alpha)\right] .
\end{aligned}
$$

Another function of the copula describing dependence is Kendall's tau. While the commonly used linear correlation is not only a function of the copula but depends also on the marginal distributions, the rank correlation Kendall's tau $\tau$, where $-1 \leq \tau \leq 1$, can be expressed in terms of the copula only,

$$
\tau(U, V)=4 \int_{0}^{1} \int_{0}^{1} C(U, V) d C-1=4 E(C(U, V))-1 .
$$

The two-parametric BB1 copula, which is used in this application, takes the following functional form,

$$
C(u, v)=\left\{1+\left[\left(u^{-\theta}-1\right)^{\delta}+\left(v^{-\theta}-1\right)^{\delta}\right]^{1 / \delta}\right\}^{-1 / \theta},
$$


where $\theta>0$ and $\delta \geq 1$, see Joe (1997) for details. The BB1 copula nests two widely used one-parametric Archimedean copulas, the Gumbel and the Clayton. The Gumbel is the limit of the BB1 for $\theta \rightarrow 0$, the Clayton arises when $\delta=1$. The BB1 can display positive and different lower and upper tail dependence and has a closed form for Kendall's tau. Lower and upper tail dependence, and Kendall's tau for the BB1 copula are

$$
\begin{aligned}
\lambda_{L} & =2^{-1 /(\theta \delta)}, \\
\lambda_{U} & =2-2^{1 / \delta}, \\
\tau & =1-\frac{2}{\delta(\theta+2)} .
\end{aligned}
$$

The estimation procedure employs maximum likelihood. Since we do not want to impose specific forms of the univariate marginal distributions, we use empirical marginal distribution functions. For statistical properties of the resulting estimators see Genest and Rivest (1993) and Genest et al (1995). For an application of copulas in international stock markets, see for example Fortin and Kuzmics (2002). 


\section{References}

AlesiI, G. (2005): "VaR in Real Options Analysis," Review of Financial Economics, 14, 189-208.

Annaert, J., G. Deelstra, D. Heyman, and M. Vanmaele (2006): "Risk Managament of a Bond Portfolio Using Options," Mathematics and Economics, in press.

Artzner, P., F. Delbaen, J. Eber, and D. Heath (1997): "Thinking Coherently," Risk, $10,68-71$.

Best, M., And J. Hlouskova (2000): "The efficient frontier for bounded assets," Mathematical Methods of Operations Research, 52, 195-212.

Bogentoft, E., H. Romeijn, and S. Uryasev (2001): "Asset/Liability Management for Pension Funds Using CVaR Constraints," Journal of Risk, pp. 57-71.

Chladná, Z., M. Chladný, K. Möllersten, and M. Obersteiner (2004): "Investment under Multiple Uncertainties," Interim Report IR-04-077, International Institute of Applied Systems Analysis.

de Jong, C., A. Oosterom, and K. Walet (2004): "Dealing with Emissions," in Managing Energy Price Risk - The New Challenges and Solutions, ed. by V. Kaminski, Risk Books. Barclay, Division of Incisive Financial Planning Ltd., 3 edn.

DiXit, A., And R. Pindyck (1994): Investment under Uncertainty. Princeton University Press, Princeton.

Doege, J., P. Schiltknecht, and H.-J. Lüthi (2006): "Risk Management of Power Portfolios and Valuation of Flexibility," OR Spectrum, 28, 267-287.

Farzin, Y., K. Huisman, And P. Kort (1998): "Optimal Timing of Technology Adoption," Journal of Economic Dynamics and Control, 22, 779-799.

Fichtner, W., M. GöBelt, And O. Rentz (2002): "Ein Modell zur strategischen Investitions- und Produktionsplanung bei Energieversorgern unter Berücksichtung von Unsicherheiten," ZfE - Zeitschrift für Energiewirtschaft, 26(3), 181-192.

Fleten, S., K. Maribu, and I. Wangensteen (2006): "Optimal Investment Strategies in Decentralized Renewable Power Generation under Uncertainty," Energy, in press(corrected proof).

Fortin, I., And C. Kuzmics (2002): “Tail-Dependence in Stock-Return Pairs," International Journal of Intelligent Systems in Accounting, Finance ES Management, 11, 89-107.

Fuss, S., J. Szolgayova, M. Gusti, and M. Obersteiner (2006a): "The Effects of Learning on Investment under Market and Climate Policy Uncertainty," Working paper, International Institute of Applied Systems Analysis.

(2006b): "Investment Response to Uncertainty in Regulation in the Electricity Sector," Interim Report IR-06-xxx, International Institute of Applied Systems Analysis. 
Genest, C., K. Ghoudi, and L.-P. Rivest (1995): "A Semiparametric Estimation Procedure of Dependence Parameters in Multivariate Families of Distributions," Biometrica, $82,7543-552$.

Genest, C., And L.-P. Rivest (1993): "Statistical Inference Procedures for Bivariate Archimedean Copulas," Journal of American Statistical Association, 88, 1034-1043.

Hlouskova, J., S. Kossmeier, M. Obersteiner, and A. Schnabl (2005): "Real Options and the Value of Generation Capacity in the German Electricity Market," Review of Financial Economics, 14(3-4), 297-310.

International Energy Agency (2005): Projected Costs of Generating Electricity 2005 Update. OECD Nuclear Energy Agency, Paris.

Joe, H. (1997): Multivariate Models and Dependence Concepts. Chapman and Hall, London.

Kiriyama, E., And A. Suzuki (2004): "Use of Real Options in Nuclear Power Plant Valuation in the Presence of Uncertainty with CO2 Emission Credit," Journal of Nuclear Science and Technology, 41(7), 756-764.

Krokhmal, P., J. Palmquist, and S. Uryasev (2001): "Portfolio Optimization with Conditional Value-at-Risk Objective and Constraints," Journal of Risk, 4, 43-68.

Krokhmal, P., S. Uryasev, and G. Zrazhevsky (2003): "Numerical Comparison of CVaR and CDaR Approaches: Application to Hedge Funds," Discussion paper, Risk Management and Financial Engineering Lab, Department of Industrial and Systems Engineering University of Florida.

Kulatilaka, N. (1988): "Valuing the Flexibility of Flezible Manufacturing Systems," IEEE Transactions on Engineering Management, 35(4), 250-257.

Kumbaroglu, G., R. Madlener, and M. Demirel (2004): "A Real Options Evaluation Model for the Diffusion Prospects of New Renewable Power Generation Technologies," Working paper no. 35, Centre for Energy Policy and Economics Working Papers.

Laurikka, H. (2004): "The Impact of Climate Policy on Heat and Power Capacity Investment Decisions," in Proceedings of the Workshop "Business and Emissions Trading", ed. by B. Hansjürgens. forthcoming, Wittenberg, Germany.

Laurikka, H., And T. Koljonen (2006): "Emissions Trading and Investment Decisions in the Power Sector - a Case Study of Finland," Energy Policy, 34, 1063-1074.

Liu, J., C. Men, V. Cabrera, S. Uryasev, and C. Fraisse (2006): "CVaR Model for Optimizing Crop Insurance under Climate Variability," Discussion paper, Risk Management and Financial Engineering Lab, Department of Industrial and Systems Engineering University of Florida.

Madlener, R., And W. Gao (2005): "Renewable Energy Policy in the Presence of Innovation: Does Pre-commitment by the Government Matter?," Working paper no. 46, Centre for Energy Policy and Economics Working Papers.

Markowitz, H. (1952): "Portfolio Selection," Journal of Finance, 7(1), 77-91. 
(1959): Portfolio Selection: Efficient Diversification of Investments. Wiley.

McDonald, R., And D. Siegel (1986): "The Value of Waiting to Invest," Quarterly Journal of Economics, 101, 707-723.

Merton, R. (1973): "The Theory of Rational Option Pricing," Journal of Economic Management Science, 4, 141-183.

Messner, S., and M. Strubegger (1995): "User's Guide for MESSAGE III," Wp 95-69, International Institute for Applied Systems Analysis.

Murto, P. (2006): "Timing of Investment under Technological and Revenue-Related Uncertainties," Journal of Economic Dynamics and Control, in press.

Nelsen, R. (2006): An Introduction to Copulas. Springer, Berlin, 2nd edn.

On Banking Supervision, B. C. (2003): "Trends in Risk Integration and Aggregation," Discussion paper, Bank for International Settlements.

(2006): "International Convergence of Capital Measurement and Capital Standards," Discussion paper, Bank for International Settlements.

Palmquist, J., S. Uryasev, and P. Krokhmal (2002): "Portfolio Optimization with Conditional Value-at-Risk Objective and Constraints," The Journal of Risk, 4(2).

Pindyck, R. (1988): "Irreversible Investment, Capacity Choice, and the Value of the Firm," American Economic Review, 79, 969-985.

(1991): "Irreversibility, Uncertainty and Investment," Journal of Economic Literature, $29,1110-1152$.

- (1993): "Investments of Uncertain Cost," Journal of Financial Economics, 34, 53-76.

Reedman, L., P. Graham, and P. Coombes (2006): "Using a Real Options Approach to Model Technology Adoption Under Carbon Price Uncertainty: An Application to the Australian Electricity Generation Sector," The Economic Record, 82(special issue), 64-73.

Riahi, K., A. Grübler, and N. Nakicenovic (2006): "Scenarios of Long-term Socioeconomic and Environmental Development under Climate Stabilization," Technological Forecasting and Social Change, article in press(special issue).

Rockafellar, R., and S. URyasev (2000): "Optimization of Coditional Value at Risk," Journal of Risk, 2, 21-42.

- (2002): "Conditional Value at Risk for General Loss Distributions," Journal of Banking and Finance, 26, 1443-1471.

Schnitkey, G., B. Sherrick, and S. Irwin (2004): "The Performance of Conditional Value-at-Risk Versus Value-at-Risk in Ranking Crop Insurance Alternatives," Discussion paper, Department of Agricultural and Consumer Economics University of Illinois at Urbana-Champaign. 
Schwartz, E., And L. Trigeorgis (2001): Real Options and Investment under Uncertainty: Classical Readings and Recent Contributions. The MIT Press, Cambridge/Mass.

Spangardt, G. Lucht, M., and E. Handschin (2006): "Applications for stochastic optimization in the power industry," Electrical Engineering, 88, 177-182.

Stern, N. (2006): "The Economics of Climate Change," Discussion paper, Cabinet Office HM Treasury.

Topaloglou, N., H. Vladimirou, and S. Zenios (2003): "CVaR Models with Selective Hedging for International Asset Allocation," Journal of Banking and Finance, 26(7), 15351561 .

Trigeorgis, L. (1996): Real Options: Managerial Flexibility and Strategy in Resource Allocation. The MIT Press, Cambridge/Mass.

Tseng, C., AND G. BARZ (2002): "Short-term Generation Asset Valuation: A Real Options Approach," Operations Research, 50(2), 297-310.

Unger, G., And H.-J. LÜthi (2002): "Power Portfolio Optimization and the Importance of Operational Flexibility," Discussion paper, IFOR, ETH Zentrum. 
Authors: Ines Fortin, Sabine Fuss, Jaroslava Hlouskova, Nikolay Khabarov, Michael Obersteiner, Jana Szolgayova

Title: An Integrated CVaR and Real Options Approach to Investments in the Energy Sector

Reihe Ökonomie / Economics Series 209

Editor: Robert M. Kunst (Econometrics)

Associate Editors: Walter Fisher (Macroeconomics), Klaus Ritzberger (Microeconomics)

ISSN: 1605-7996

(C) 2007 by the Department of Economics and Finance, Institute for Advanced Studies (IHS),

Stumpergasse 56, A-1060 Vienna • 㿿 +43 $159991-0 \bullet$ Fax +43 1 59991-555 • http://www.ihs.ac.at 
ISSN: 1605-7996 